\title{
The impact of changes in
}

\section{cartography and mapping on the}

\author{
selection of cartographic materials
}

in New Zealand map libraries

\author{
by Mark J. M. Bagnall
}

Submitted to the School of Information Management,

Victoria University of Wellington

in partial fulfilment of the requirements for the degree of Master of Library and Information Studies 


\begin{abstract}
Changes to cartography and mapping in New Zealand have had impacts on map library identification, evaluation and selection of maps and other tools that convey spatial data. In semi-structured interviews, five map librarians gave their views on how changes to cartography and mapping affects the selection of cartographic materials. Data gathered from managers/technicians of geographic information systems laboratories were also used in the research. The results indicate that New Zealand's specialist map libraries are developing their collections and services to include electronic cartographic resources. This collection development tends not to be the result of forward looking collection policies that outline a vision and strategies for integrating hardcopy and electronic cartographic materials into collections and services. The results also indicate that map librarians are adapting their selection practices to cater for the special requirements of new cartographic information resources and to overcome some of the difficulties related to the reshaping of the mapping industry in New Zealand.
\end{abstract}




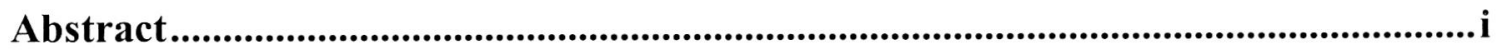

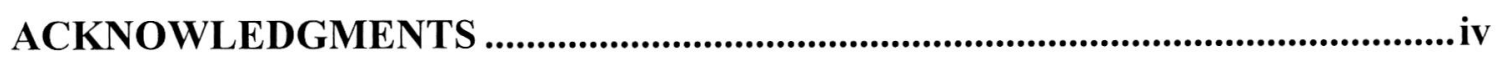

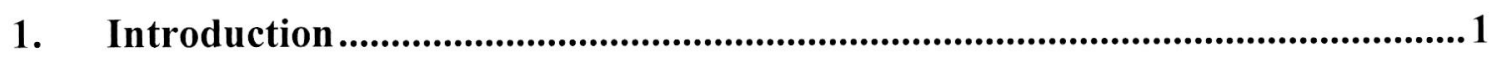

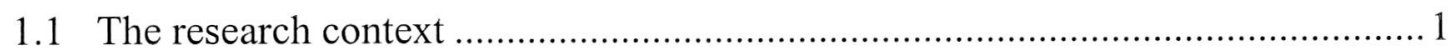

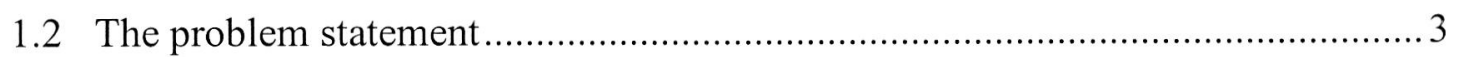

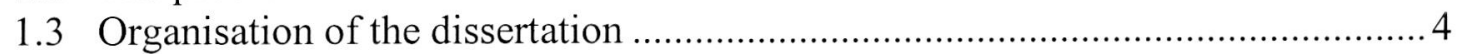

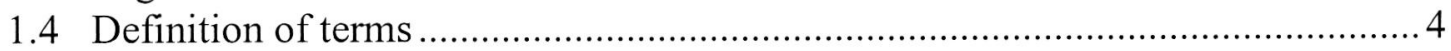

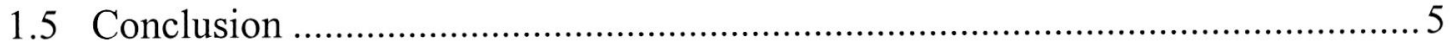

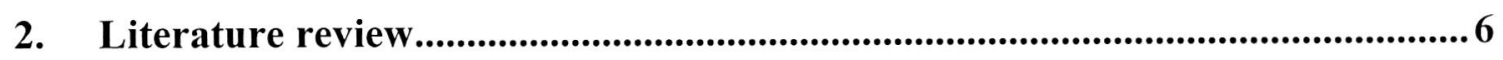

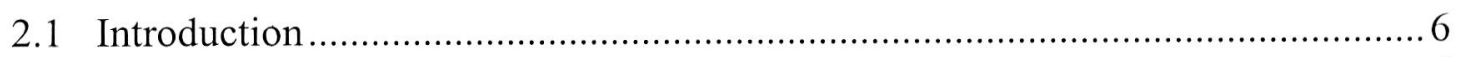

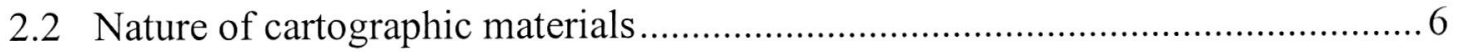

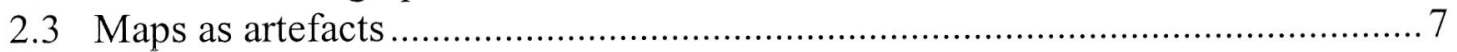

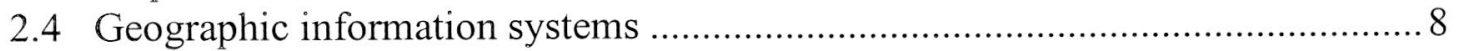

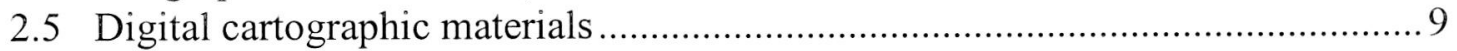

2.6 Cartographic materials defined in terms of their subject content ...................... 11

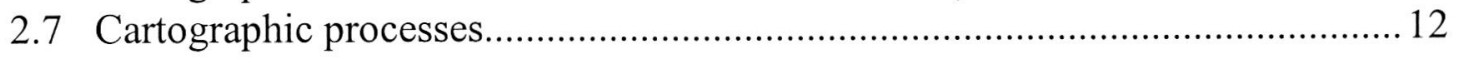

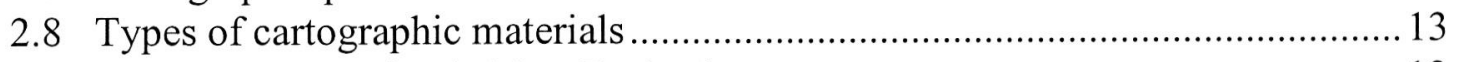

2.9 Changes to mapping in New Zealand ……................................................... 13

2.10 General context of mapping in New Zealand ............................................ 15

2.11 Propriety and intellectual property rights issues ......................................... 16

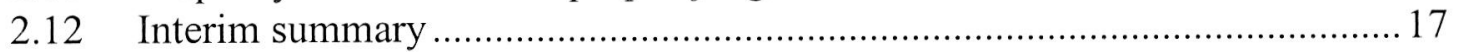

2.13 A theoretical model of selection practices ................................................... 18

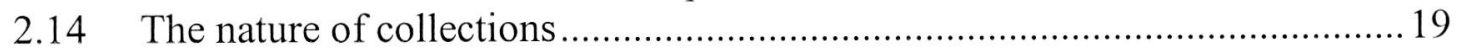

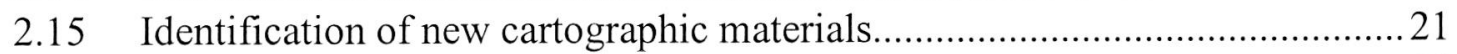

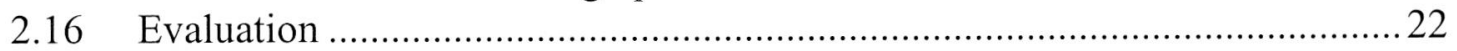

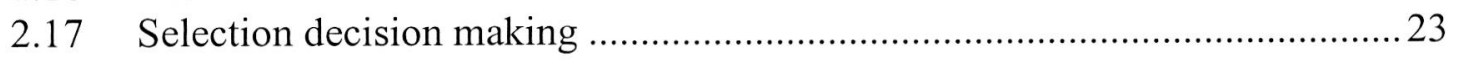

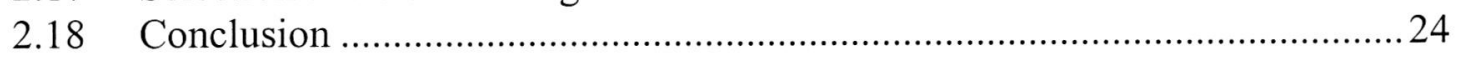

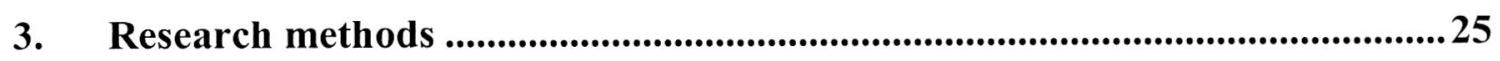

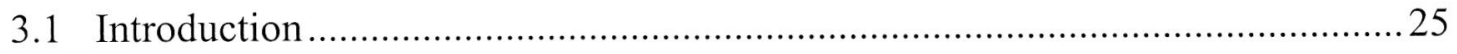

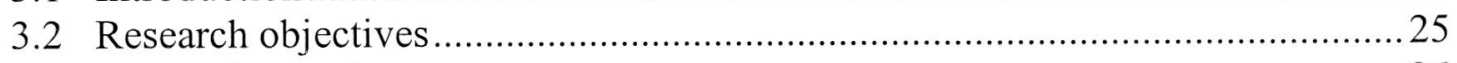

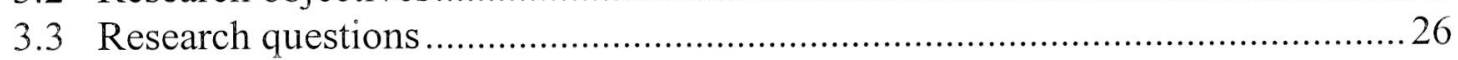

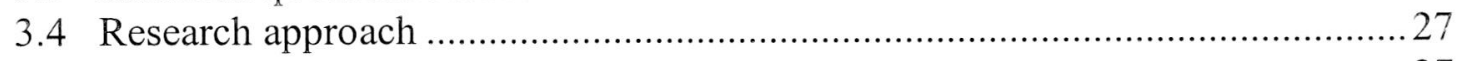

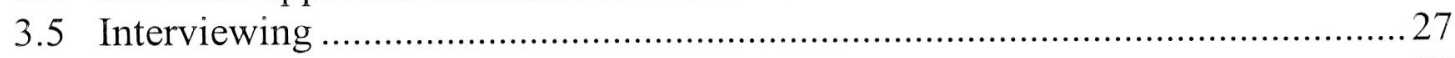

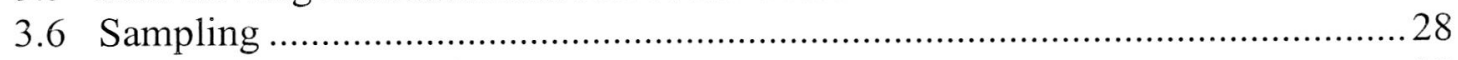

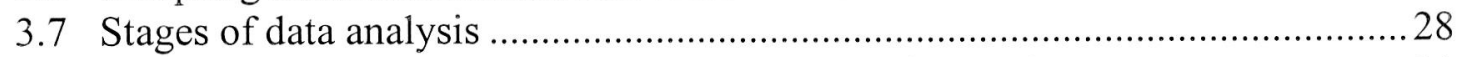

3.8 Ethical considerations and presentation of interviewee data ............................ 31

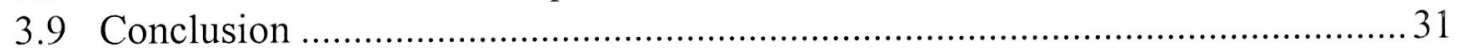


4. Changes in cartography and mapping - perspectives of map librarians ......32

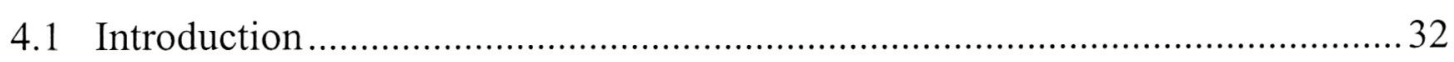

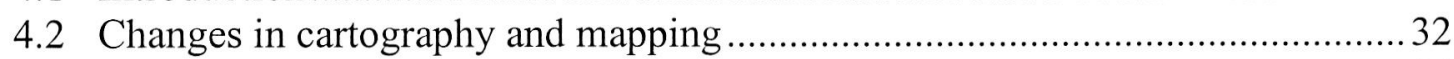

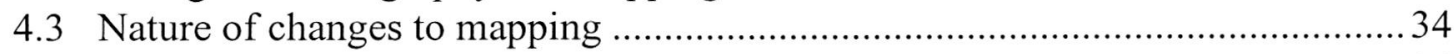

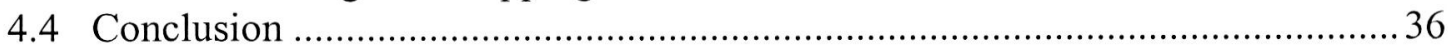

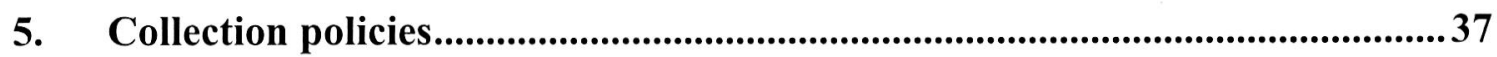

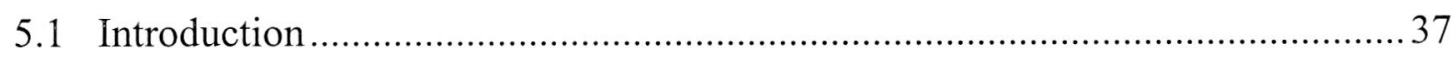

5.2 Collection development policy and electronic materials .................................. 37

5.3 Nature and scope of the map libraries' collections ........................................... 38

5.4 Future direction - digital mapping and online access to existing maps...............39

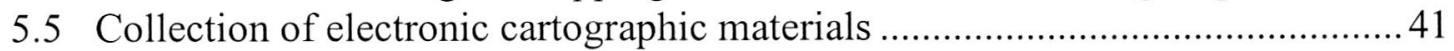

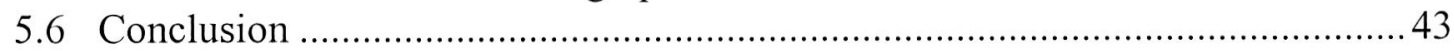

6. Identification process of cartographic materials.....................................................44

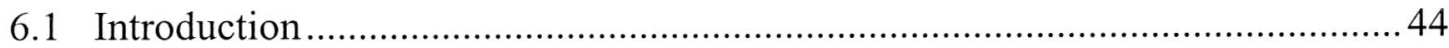

6.2 Identification of sources of cartographic materials .......................................... 44

6.3 Information about editions and versions of cartographic materials .....................45

6.4 Tools for the identification of cartographic materials ........................................46

6.4.1 National bibliography and other bibliographies..................................... 46

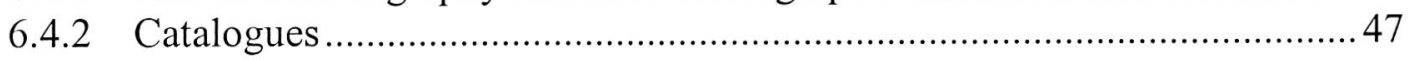

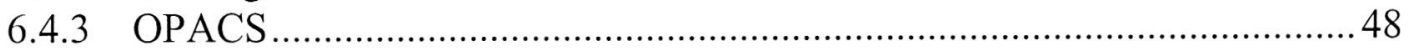

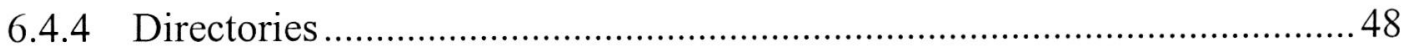

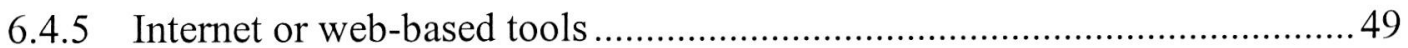

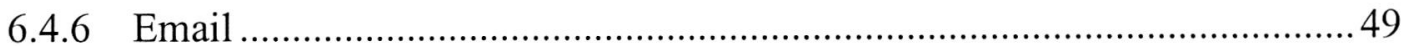

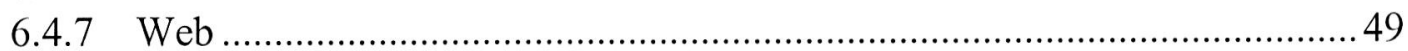

6.4.8 Other sources of information about cartographic materials .......................50

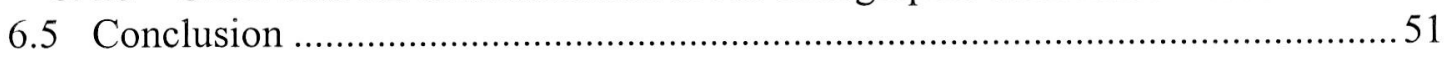

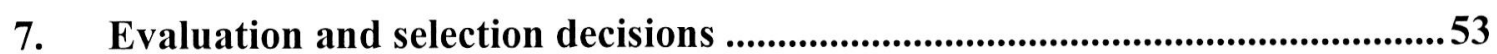

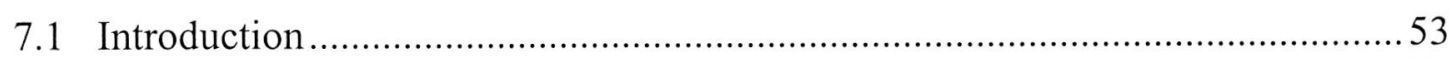

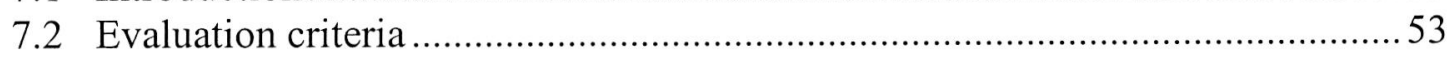

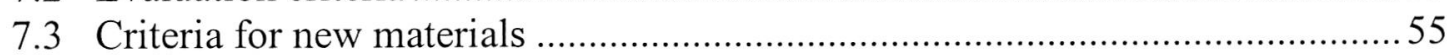

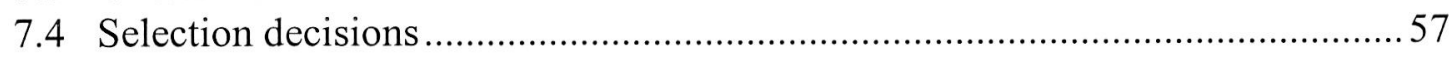

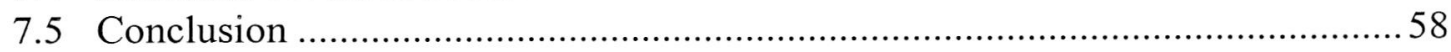

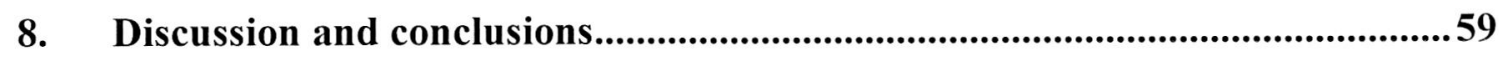

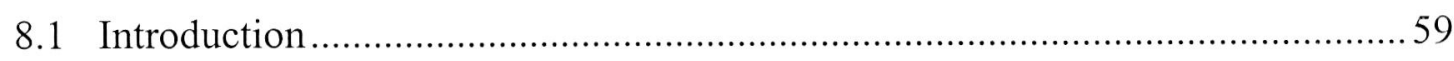

8.2 Policy formation and the nature of current collections .....................................59

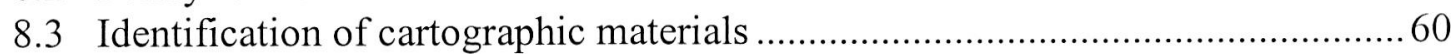

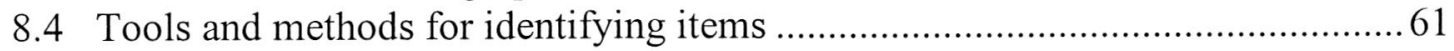

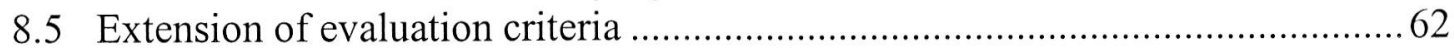

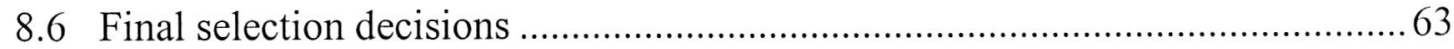

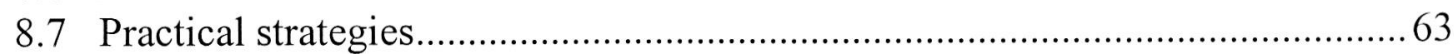

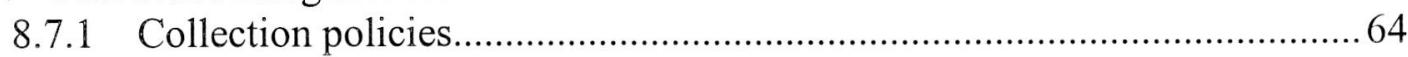

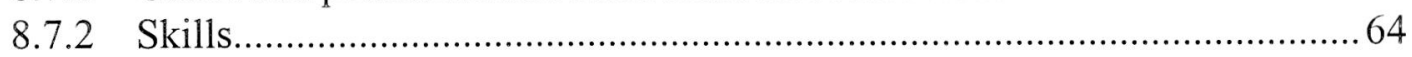

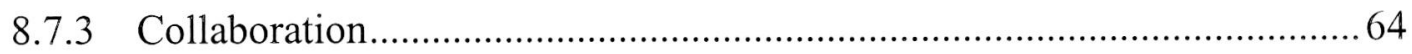

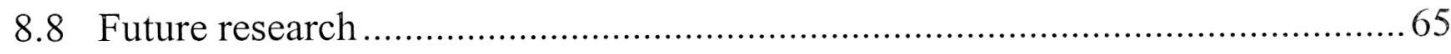


Appendices

.70

Appendix One: Information sheet to accompany consent form. .70

Appendix Two: Questions for GIS laboratory managers or technicians. 74

\section{ACKNOWLEDGMENTS}

I would like to thank the participants in my research. I also wish to thank Dr Dan Dorner for his supervision, especially for reading and commenting on my drafts and his enthusiasm for my project.

Special thanks go to Andrea, Zoe and Joshua for putting up with my seemingly never-ending tiredness. 


\section{INTRODUCTION}

\subsection{The research context}

Changes in technology and techniques used in cartography, ranging from data gathering to map design and map production, have led to debates on the nature of maps and concepts that define the methods and means of conveying spatial information (Fairbairn, 1993; Vasiliev, Freundschuh, Mark, Theisen, and McAvoy, 1990). At the same time, these developments in cartography have been rivalled by advances in computer and information technology. Digital databases capable of sophisticated manipulation and analysis of spatial information (processed data) have been commercially available in CD-Roms, and other formats, for the last ten years. Previously, the paper map was central to collection building activities in map libraries. The concept 'map' defined the published form of spatial information. Now, in the context of these changes, the 'map' has become one of many forms of communication that conveys spatial information.

Recent changes in cartography theory and techniques and changes in mapping have affected specialist map libraries ${ }^{1}$. Map libraries emerged because of the need for the specialist care and services required to store, organise and provide access to maps (Ristow, 1980). The need for specialist technical and user services for maps remains today as a result of the range and number of cartographic materials that are available. Today, map libraries have become "nodes of access" to a range of cartographic materials (Forer, 1993, 114), as an ever increasing proportion of their services moves towards accessing data via the Internet or local computer networks (Perkins, 2001). They have also become increasingly important as archives of historic spatial information, both digital and hardcopy (Forer, 2001). Although the overall role of map libraries of providing users with access to spatial information remains (Perkins, 1994), 
the nature and extent of the collections and services are changing. As Forer $(1993,105)$ wrote, "map libraries are repositories of spatial knowledge rather than maps". This perception of the role of map libraries reflects the move away from an emphasis on objects to intellectual content (discussed in more detail below) which is also evident in librarianship in general (Budd and Harloe, 1997; Dorner, 2001).

Changes in cartography theory and practices have also furnished the opportunity for reorganisation of the mapping agencies and industry, which has occurred in most western countries in the last decade (see Rhind, 1997). Mapping in New Zealand has not been exempt (Robertson and Gartner, 1997; Forer, 2001). During the late 1980s and 1990s, technological changes and political and economic changes in New Zealand have been drivers of substantial restructuring of New Zealand's official mapping agencies. For instance, the regulatory and commercial functions of New Zealand's national mapping agency, undertaken by the Department of Survey and Land Information, was split and formed the basis of two separate entities in the 1990s. The former remained a government agency, the latter became a commercial organisation. The restructuring of official mapping has influenced access to spatial data and the publication of cartographic materials by other official, non-official and commercial mapping organisations.

"Libraries are dependent on four main conditions", according to Hazen (1990, 279), namely their "institutional context, user demands, techniques and technologies, and existing scholarship and patterns of scholarly communication". Above all other factors, Hazen $(1990,294)$ suggested that selection processes are affected by new technologies. Aforementioned recent changes in mapping techniques and technologies and patterns of communication of spatial information are having a profound affect on map libraries' collections and services (Parry and Perkins, 2001). In this context, a range of views are held about the future success and direction of map libraries. Their success seems to depend on whether map librarians can develop "practical mechanisms" to create institutions that can "successfully remake" themselves in response to the challenges of the changes in cartography (Perkins and Parry, 2001). This building process begins with selection.

Monroe $(1997,106)$ argued that "almost any library collection is built through the selection of certain items from a wider universe of materials available" and that 
"selection, whether of material containing information or of paths to information, lies at the heart of library service". Larsgaard $(1998,1)$ wrote that "although spatial-data collections $^{2}$ come in many different sizes, organizations, and facilities, the beginning problem for each is selection". In considering the future services of map libraries, Perkins (1994) contended that the quality of their services will depend on the ability of selectors to select from the range of available spatial information resources.

A scan of the literature indicates that little is known about how specialist map libraries in New Zealand have responded to changes that have occurred in mapping in New Zealand. In the 1970s and 1980s, Barton (e.g., 1978, 1979, 1981) regularly wrote articles about map selection and acquisition in New Zealand, focusing specifically on the classification of different maps by their source of origin (ie. official, non-official and commercial mapping organisations). More recently, Parry and Perkins (2000) described the availability of, and ways of accessing, cartographic materials in New Zealand. They classified products according to their source of origin, as did Barton (1978), and also according to the types of products (e.g., digital spatial data). This literature gives an overview of sources of cartographic materials, however, it provides no insight into the selection practices of specialist map libraries in New Zealand. Only Barton (1981) has written about the nature of collections in specialist map libraries in New Zealand. However, this was written before digital cartographic materials were widely available. It is evident that there is a distinct lack of research on the selection practices of specialist map libraries in New Zealand. There is also a need for a formal study that aims to identify factors that impinge upon the selection process.

\section{$1.2 \quad$ The problem statement}

With these gaps in research in mind, in this research project I sought to describe the kind of work that selectors of cartographic materials do and to describe how their work has been affected by changes in cartography and mapping ${ }^{3}$. It is important for selectors of cartographic materials to understand not only changes in technology and techniques and in approaches to communication of spatial information, but also other libraries

2 Larsgaard (1998, xvii) sometimes uses 'spatial data' instead of the phrase 'cartographic materials', because some persons believe "that the word 'cartographic' somehow limited the discussion to maps, which it does not".

3 It does not attempt to describe or prescribe selection practices in map librarianship, or to level specific criticisms at map librarians in New Zealand. 
practices. Through the views of other map librarians, they may gain insights into factors and processes that affect their work and through those insights be able to create better strategies for developing their collections and their corresponding selection practices.

\subsection{Organisation of the dissertation}

To gain insights into the problem area outlined above, this research project is organised in the following way:

Chapter two reviews literature on cartography and map librarianship. The first section of chapter two discusses significant changes that have occurred in cartography and mapping both overseas and in New Zealand in the last two decades. The second section of chapter two begins with an outline of Edelman's (1979) model of selection practices which I use as a framework of analysis for my research project, and a framework for organising the dissertation. Then I draw on literature on both map librarianship and librarianship in general in a review current approaches to selection practices. Chapter three describes a research approach that provides the kind of data that is relevant to the exploratory nature of the research project and that provides the depth of data that is needed given the small number of research participants.

Chapter four describes external factors relating to changes in cartography and mapping that influence the selection of cartographic materials according to the views of the interviewees. The subsequent substantive chapters, chapters five, six and seven, describe the interviewees' collection policies and selection practices. The final chapter relates the findings of the substantiative chapters to other practices in map librarianship, and draws conclusions about current practices in New Zealand's specialist map libraries. It ends with a recommendations for future research.

\subsection{Definition of terms}

Before concluding this chapter, it is worth introducing some important definition of terms that I used in this dissertation.

Cartography refers to the art, science and technology of analysing, interpreting and communicating spatial relationships. 
Cartographic materials are products that convey data or information on spatial phenomena and their spatial relationships. They may be tangible (hardcopy) products, or intangible (electronic) products that can be locally or remotely accessed.

Mapping is the process of producing cartographic materials, from data gathering to design, to the production of output of spatial information.

Map libraries or map collections are libraries or collections (within larger institutions) whose core collections were/are centred on maps, and may now incorporate digital information resources.

\subsection{Conclusion}

In this chapter, I introduced the research context. In the context of changes in cartography and mapping, there are expectations that map libraries have to make changes to their collections and services. I outlined a research problem and the overall goal of my research project, which is to describe the work of selectors of cartographic materials and how changes in cartography and mapping have impinged on their work. 


\section{LITERATURE REVIEW}

\section{CARTOGRAPHIC MATERIALS AND MAP LIBRARY SELECTION PRACTICES}

\section{$2.1 \quad$ Introduction}

Essential to developing selection practices has been understanding of the current state of the art of information sources in specific fields of intellectual endeavour and corresponding issues concerning the selection of such sources (Perkins, 1994). The aim of this literature review is to provide an overview of both of these areas. This literature review is in two sections. The first section provides an overview of general trends in the development of cartography and methods of storing and conveying spatial information. It also provides an insight into changes to approaches in mapping and the reshaping of the mapping industry in New Zealand. The second section discusses literature on current map library selection practices, including developing collection policies, identification, evaluation and the final selection decision making. At the beginning of this section I outline a conceptual model of selection practices which I use as the central theoretical framework in this research project. Next, I draw on literature on map library selection practices, and on selection practices in other types of libraries where I thought such literature contributed to the understanding of current selection practices.

\subsection{Nature of cartographic materials}

Over the last several decades, the concept of 'map' shifted emphasis from the 'form' or 'object' that contained spatial information (e.g. the printed map) to include varying emphases on the 'intellectual content' (the 'subject' and function of spatial information was independent of the means and medium though which it was conveyed). 
The following section examines various concepts of maps and other cartographic materials and this shift in emphasis to the intellectual content of cartographic materials.

\subsection{Maps as artefacts}

Until the end of the $20^{\text {th }}$ century, paper maps were the main means of conveying spatial data and information. With the introduction of, and advances made by, computers and information technology in cartography and other associated fields of study, the means and media through which spatial information is conveyed have become more diverse. Until the late 1980s, the International Cartographic Association's official concept of maps was:

Maps may be regarded as including all types of maps, charts and sections, three dimensional models and globes representing the Earth or any celestial body at any scale (International Cartographic Association, 1973, p. 1 - cited in Visvalingham, 1989, 26).

Over the 1970s and 1980s, as numerical and analytical approaches to cartography became more sophisticated, the prevailing philosophical and technical aspects of cartography were questioned (Moellering, 1984) and the map rapidly became "just one of many forms of spatial data product" (Forer, 1993, 105). As new cartographic materials that had map-like qualities developed, contemporary definitions of the concept of map, such as the above, became inadequate (Moellering, 1980). Thus, criticisms of the ICA's official concept (above), such as Visvalingham's (1989), were made. Visvalingham (1989) argued that the definition was vague and placed too much emphasis on the 'object'. This concept of map led to suggestions such as Riffe's (1970) that map images displayed on a cathode-ray tube were not maps because of their “transient nature” (Moellering, 1980, 13). Moellering (1980, 13), for example, proposed a classification of maps based on two central variables: their "direct viewability" (i.e. a graphic representation, rather than a set of data) and their "permanent tangible reality" (hardcopy as opposed to electronic):

A real map has a directly viewable cartographic image and has a permanent tangible reality (hard copy), e.g., conventional sheet map, globe, plastic relief model, computer output microfilm. 
A virtual map (type 1) has a directly viewable cartographic image but only a transient reality as has a cathode-ray tube map image, e.g., electronic map image, cognitive map (two-dimensional image).

A virtual map (type 2) has a permanent tangible reality, but cannot be directly viewed as a cartographic image. These are all hard copy media, but in all cases these products must be further processed to be made viewable, e.g., traditional field data, gazetteer, laser disk data.

A virtual map (type 3) has neither of the characteristics of the earlier classes [of virtual maps], but can be converted into a real map as readily as the other two classes of virtual maps. Computer based information in this form is usually very easily manipulated, e.g., digital data, digital terrain model, cognitive map (relational geographic information) (Adapted from Moellering, 1980, 13).

Moellering's (1980) classification explicitly set electronically rendered maps apart from what he called real maps (hardcopy) because of their 'transient reality' or the volatility of electronic media. However, Moellering (1980) suggested that virtual maps have the potential of being transformed into real maps, and indeed his classification included a database or information system that contained underlying spatial data as a class of virtual map. In the digital age, clearly this would rule out many sources of digital spatial information.

\subsection{Geographic information systems}

Forer (1993) described a range of digital cartographic materials that have become available in the last decade. Before outlining these products, it is worth briefly defining geographic information systems, which were, to all intents and purposes, the systems underlying most of those digital products. Geographic information systems are essentially databases which are specifically designed to store, handle, process and analyse georeferenced data (Goodchild, 2000). Initially, geographic information systems were developed as tools to assist in handling large amounts of geographic referenced data. "Much of the initial development of geographic information systems came from the difficulties of analysing data shown on paper maps, including such simple tasks as measuring area" (Goodchild, 2000, 303). They had an immediate impact, and their real strength and appeal were their "exploratory functions of browsing and simple statistical analysis, and more sophisticated confirmatory techniques" (Goodchild, 2000, 302). 
Two main approaches to modelling spatial reality in geographic information systems have developed. Vector models focus on describing discrete objects, and raster models are concerned with "recording what is to be found at a predetermined set of locations that may be grid cells or points" (Jones, 1997, 18). Each have their advantages and disadvantages (see Jones, 1997, 18-38 for a full description). Needless to say, map producers tend to favour vector models.

\subsection{Digital cartographic materials}

Forer (1993, 105-107) described a range of different digital products that were being developed and targeted to different markets:

(i) Digital maps - material covers a wider area than the typical single printed sheets, and software may free the user to tweak both scale and presentation. The end result is a map.

(ii) Digital spatial databases - separates the two concepts of data and display: one database can be manipulated in many ways and linked to different ideas of representation to create a legion of maps.

(iii) Remote spatial databases - networked cartographic materials;

(iv) Digital images - direct images of geographic features without cartographic interpretation; and

(v) Local digital databases - have local data capture capabilities so that database owners can input data that they themselves have captured for analysis.
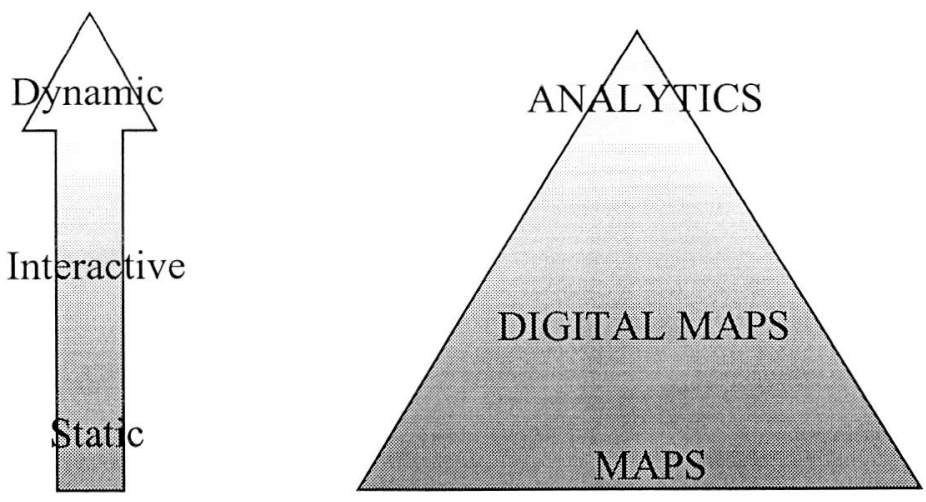

Figure 1: Range of cartographic materials

(Adapted from Forer, 1993, 106) 
The capabilities of cartographic materials, ranging from digital maps to the most sophisticated geographic information systems, can be considered in terms of the flexibility of the data or information (Forer, 1993), and can be divided into three categories: static, interactive and dynamic (Moellering, 1980) (see Figure 1, p. 9). Static content is a representation of spatial information that requires no processing to produce output; the layers of information are static and cannot be transformed. Static cartographic materials are usually oriented to the printing of hardcopy sheet maps, and therefore produce high quality output. Interactive products have hardcopy production capability, but are oriented to reasonably simple queries, for example "point-and-click access to highly customised maps, complementary graphs and diagrams, detailed explanations of data, and even the map-makers' raw data" (Monmonier, 2000, 474). Dynamic systems enable users to analyse data, including being able to incorporate time and motion variables, and to produce spatial information output to suit the particular user information requirements. This is "increasing the potential for a more interactive and exploratory map use" (Perkins and Parry, 1996, 9).

One of the main design components of cartographic materials that determined their static and dynamic qualities was the depth of the spatial data structures in them:

Every digital map has a digital database associated with it, which specifies both the phenomena being mapped and the representation devices used to map them (Forer, 1993, 105).

Nyeges (1980, cited in Moellering, 1984) identified several different layers of cartographic data, including attribute, locational data and the programming data of the software. As a general rule, the more sophisticated the programming and the greater the depth of layering of data are, the more dynamic the cartographic product.

The availability of cartographic materials via the Internet requires some special mention. As a means of distributing spatial data and maps, the Internet is increasingly being used by mapping organisations (Kraak, 2001). It is a relatively cheap method of distribution of data (Peterson, 2001) and offers website owners control over access (Kraak, 2001). One of the main advantages of using Internet spatial information resources is the hyperlinked nature of the Internet and the possibility of interaction with other Internet data and information resources (Dorling and Fairbairn, 1997; Kraak, 2001). Potentially, there are few technical limitations to providing users access to any type of digital cartographic product, ranging from static maps to dynamic systems. Some problems with gaining access to cartographic materials of the Internet are that the 
size of files of cartographic materials tends to be large. Downloading via the Internet therefore tends to be slow (Kraak, 2001). Most other limitations are the same as with any other digital information resource.

The nature of digital information raises several concerns that librarians have had to consider. The volatility of digital spatial information (Forer, 1993) and the complexity of handling a range of file formats and mediating technologies (Forer, 1993; Perkins, 1993) are some of the main concerns. Any end-user analysis of data often requires powerful computer systems because of the size of software and data files (Kraak, 2001). Given the importance of visual representation, limitations of computer monitors, such as size and fidelity of images, are also significant (Kraak, 2001). Most electronic cartographic materials that are loaded onto local computer networks or personal computers are hardware and software dependent (Parry and Perkins, 2000), which raises the concomitant concerns about the rate of obsolescence of computer platforms. One of the main advantages of gaining access to spatial data via the Internet is that most cartographic materials are "virtually platform independent" (Kraak, 2001, 104). Some of the concerns can be alleviated by the development and implementation of information management procedures or cooperative arrangements with other information user groups or representatives. Other technical concerns, such as limitations of output display, should over time be alleviated by advances in computer technology (Kraak, 2001).

\subsection{Cartographic materials defined in terms of their subject content}

If the information content of maps is defining components of maps, then what is the information content? The International Cartographic Association defined the subject content of maps as "representing the Earth or any celestial body". This concept of maps reflected the historical inheritance of cartography and its functions of navigation (wayfinding and recording exploration) and surveying (recording inventories of natural and artificial geographic features). The main subject matter of maps was information on geography whereby 'geo' means of the earth and 'graphy' means 'study of' (Collins Dictionary, 1993). In 1995, the International Cartographic Association broadened its earlier concept of the map and defined it as "a symbolised image of geographic reality, representing selected features or characteristics, resulting from the creative efforts of 
cartographers and designed for use when spatial relationships are of special relevance" (Dorling and Fairbairn, 1997, 3). As a representation of space, the data conveyed by maps are georeferenced. The information has a more or less direct relationship with a selected area of space.

Some authors suggested that changes in cartography and other similar mapping techniques meant that subject matter was much broader than geographic information. Indeed, some authors went as far as suggesting that the subject of maps was unlimited. Robinson, Sale, Morrison, and Meuhrcke $(1984,3)$ wrote that the "graphic representation of spatial relationships and spatial forms is what we call a map". Vasvalingham $(1989,30)$ wrote that maps depict "spatial reality". MacEachen $(1995,1)$ went as far as defining the concept of maps as one means of "spatial representation". Space was defined as both abstract and real (earth and celestial) space (Robinson et al., 1984). Central to the subject concept of maps was, then, that the nature or characteristics of natural or artificial features and their relationship with other features in space were clearly represented.

Until the latter $20^{\text {th }}$ century, they were the most effective ways of conveying spatial information, because such information was less effectively conveyed between information producers and users through text (Forer, 1993). Nowadays, spatial information can be conveyed via a large variety of tools, and not just paper or digital map and map- like objects. Indeed, Forer $(1993,105)$ argued that "any map is just one representation of an underlying spatial database, and these databases are becoming the key information product".

\subsection{Cartographic processes}

The development of computer-generated cartographic materials has revived concerns about the processes of cartographic representation. Kelly (1993) argued that the science of cartography dominated the art of cartography during the early developmental stages of computer and automated cartography to the detriment of the aesthetic, design and visual qualities of maps. Robinson et al. $(1984,5)$ suggested that four qualities were essential to the 'informational' integrity of representations of space. The first of the qualities was that maps are drawn to scale. "Most maps are reductions, and thus a map is usually smaller than the region it portrays" (Robinson et al., 1984, 5). The second was that a form of projection is used to assist in transforming the "shape of 
the earth's surface on to a flat plane or other medium" (Robinson et al., 1984, 5). The third was that all georeferenced data involves abstractions of reality since not all spatial reality can be represented. This process required the producer of the cartographic product to make a decision about what should be included and excluded, and how those features and their relationships to other features should be represented. Finally, "all maps employ signs to designate elements of reality" (Robinson et al., 1984, 6). Therefore, what distinguishes a (hardcopy and digital) map from other tools for conveying spatial data is that it is a graphic representation of spatial reality that incorporates these four cartographic qualities, as opposed to tools that convey spatial data and have a capacity to analyse and present that data. Sometimes the output of such tools have some of the four cartographic qualities (Parry, 1999).

\subsection{Types of cartographic materials}

The two main types of cartographic materials are general purpose or topographic and thematic cartographic materials (Parry, 1999). General purpose cartographic materials indicate the true location and shape of different nature and artificial geographic features such as roads, buildings, and hills, rivers and forests. In thematic cartographic materials, topographic data are combined with attribute data relating to specific subject themes such as data about migration trends. The real benefit of digital spatial information is in the development of thematic cartography products where thematic data are "spatially encoded" (Parry, 1999, 266). Parry (1999) suggested that by such means, an endless variety of maps or output can be produced according to users' questions or information requirements.

\subsection{Changes to mapping in New Zealand ${ }^{4}$}

In the early 1990s, the policy and regulatory functions, and the official (e.g., national database maintenance) and commercial mapping (e.g., consultancy and publishing) functions that were performed on behalf of the New Zealand government were centralised in one organisation, the Department of Lands and Survey. It was fully

4 Three types of organisation are involved in cartographic publishing in New Zealand: official (national, regional and local government agencies), non-official (non-profit making) and commercial organisations (Barton, 1989; Parry and Perkins, 2000). 
government funded and sought to systematically gather data, keep a database of spatial data on the lands of New Zealand and its off-shore islands, and publish maps and other cartographic materials (e.g., Atlas of New Zealand) for a generalised civil and military readership, so that "customers could have any product or service as long as it was in the form that it was already produced, since no variations or exceptions were allowed" (Robertson and Gartner, 1997, 248).

In the 1990s, New Zealand's official mapping agencies were restructured "from a culture and tradition of a stable and highly regulated environment", to a "client- and market-oriented" work environment (Robertson and Gartner, 1997, 248). This approach was progressively implemented over five years. It was first reshaped into the Department of Survey and Land Information (DoSLI). Since 1996, New Zealand's national mapping agency has been Land Information New Zealand (LINZ), whose main functions have been to provide advice to the government, to purchase spatial data on behalf of the government, and to manage a national database of spatial information on lands and waters of New Zealand and its off-shore islands (Robertson and Gartner, 1997). Several other government-owned companies (State-Owned Enterprises) are responsible for the publishing of spatial data on specific subjects. For example, in 1996, the Royal New Zealand Navy (RNZN) was responsible for publishing hydrographic charts of the New Zealand coast and of sealanes linking New Zealand with the Pacific Islands. LINZ is now responsible for these charts, although the data is still gathered by the RNZN.

LINZ itself has a variety of cartographic materials (Aitken, O’Malley, and MacFarlane, 1993). In addition to its national spatial database, LINZ also provides other nationally significant databases, such as New Zealand's cadastral database and CD-Rom products (see Aitken et al., 1993). Map libraries need to consider their role in providing user access to the range of spatial data products available.

In the future, there is an expectation that the mapping processes will become increasingly automated and that, as generalisation computer software develops, these aspects of management of the national database will become automated (to some extent this is already occurring). Databases will be connected to remote devices (e.g., satellites) that gather spatial data, and spatial data will be automatically updated in realtime. Topographic information could be produced as output (hardcopy or digital) on demand within moments of data collection (Howard, Pickering, and Mole, 1999). The 
automation of cartographic processes has implications for the provision of access to current and especially historical spatial data.

\subsection{General context of mapping in New Zealand}

The restructuring of New Zealand's official mapping agencies has occurred at a time when there is a general shift in mapping in many western countries from large scale institutional mapping focused on a generalised readership. Increasingly, mapping organisations produce cartographic materials on a small scale developed for specific subject areas and user groups (Dorling and Fairbairn, 1997; Perkins and Parry, 1996). Robertson and Gartner (1997) indicated that this shift had to some extent only been possible with recent developments in cartography technologies and practices.

Changes in mapping, in particular the move from large print runs of maps, to communicate the lie of the land and its natural and artificial features, to printing ondemand spatial information, has led to a change of emphasis in cartography. Three trends have developed. National mapping agencies and other mapping organisations are developing a range of cartographic materials according to consumer demand. LINZ, for example, regularly canvases various interest groups to ascertain their cartographic information needs (Robertson and Gartner, 1997). Secondly, mapping organisations have also moved towards producing maps on demand. Interactive digital cartographic materials are used to produce output, digital or hardcopy, on demand in map form using cartographic standards (ie. scale, projection, etc. ) (Howard et al., 1999). Output can be 'designed' by the user on the spot and produced within minutes, or longer depending on the quality of the available computer or printer. Thirdly, "increasingly maps are being drawn by individuals for themselves rather than by companies and government organizations" (Dorling and Fairbairn, 1997, 156). There has been an increase in individual interest in maps and map production, which has largely been due to the boom in personal computer hardware and software, especially of desk-top publishing software. The personal computer boom has enabled individuals to undertake sophisticated computer tasks. 


\subsection{Propriety and intellectual property rights issues}

The funding of the spatial information infrastructure and nature of mapping raises issues about the propriety and intellectual property rights in regard to spatial information. During the restructuring period, a cost recovery regime for LINZ's activities, including the distribution of spatial data, was progressively put in place and government funding of the department was reduced. In a market-oriented environment, the selling of the intellectual rights to spatial data was one of LINZ's main sources of income, and the data are keenly guarded because spatial data are frequently sold on the basis of the ability to add value to that data (Forer, 1993). Most vendors (e.g. LINZ) of spatial data and information provided access to their systems on short term leases so that they could assert control over their intellectual content. Forer (1993) indicated that in such a climate it was difficult to secure on-going access to spatial data.

The market-oriented model lasted until the end of 1999, when a public good approach to the provision of access to national spatial data was implemented (Forer, 2001). In September 1999, the Minister of Land Information New Zealand (1999) announced the new pricing regime for cartographic data:

Under the new pricing regime, all copyright fees for the reproduction of LINZ-held digital data, topographic maps and aerial photographs will be abolished. Previously a large map producer could have paid copyright fees of around $\$ 100,000$ per year. Now the fee for digital data will only reflect the cost of its dissemination (Minister of Land Information New Zealand, 1999).

The Crown sought to enforce its "intellectual property rights only through acknowledgment by the user, and to make all pertinent government data, as well as the topographic spatial data holdings, available on a 'transfer cost only' basis' (Forer, 2001, 198). LINZ did not seek to recover the cost of producing the data, or to price the potential of data to other mapping agencies. This policy removed most of the compliance costs associated with negotiating intellectual property rights, and consequently has stimulated the production of many new spatial information products and "encouraged a range of government departments to provide web-enabled public access to data files such as census and traffic count data" (Forer, 2001, 199). It also enables anyone to make copies of topographic data or information that are published by New Zealand's official mapping agencies. 
Since there are now few restrictions on the use of these data, intellectual property rights are now mainly asserted on the value-added information developed by other, mainly commercial mapping agencies. More sophisticated end-user cartographic materials also require sophisticated software, which are specifically developed for those products. Apart from the underlying topographic data, users may have to negotiate terms of access to all other layers of data (including software), or have to negotiate rights to each layer separately. Forer (2001) suggested that map libraries might negotiate special agreements with the mapping agencies to act as agents and provide access to information for their users at no or minimal cost, now that there is less need to be concerned about copyright restrictions.

\subsection{Interim summary}

So far the literature review has focused on the general context of map librarianship in the past decades. Until the last two decades, paper maps were still the main method for storing and conveying spatial data and information. Developments in cartography and other related fields of such as geographic information systems have give rise to a range of new methods of storing, conveying and analysing spatial information.

The freeing up of copyright restrictions on spatial data in New Zealand and the decrease in costs of purchasing topographic data from official mapping agencies have effectively led to a burgeoning of organisations producing cartographic materials, published cartographic materials and cartographic materials being produced for specific commercial information needs. In conclusion, the first section indicates that paper maps are no longer the main tool or medium through which spatial information is stored or conveyed and that the restructuring of New Zealand's official mapping agencies has made digital cartographic data and information more widely available and at a lower cost.

The following section describes recent changes in map librarianship. However, before reviewing changes in map librarianship and similar changes in librarianship in general, I introduce Edelman's (1979) model of selection processes, which informs the organisation and analysis of this research project. Where possible literature specifically dealing with map librarianship is used, otherwise relevant literature about other types of libraries is used. 


\subsection{A theoretical model of selection practices}

Hazen $(1990,296)$ argued that the more successful approaches to researching the selection process incorporate "fairly detailed treatments of single elements affecting the [selection] process". They also tended to "begin from the "top down", and link fairly broad analyses of collection development (planning function and documents), its purposes and operations, to the conceptually subordinate areas of selection and acquisition" (Hazen, 1990, 285).

Edelman's (1979) model of the selection process is recognised for its "incisiveness" (Hazen, 1990, 285) and continued usefulness (Virgil, Blake, and Surprenant, 2000). Its purpose was to help "understand the concepts and activities involved in selection" (Edelman, 1979, 33). Edelman (1979) identified three levels of activity:

(1) Policy formation is the planning process through which a library decides what to collect.

(2) The result is a collection development policy that establishes collecting goals and priorities. A collection development policy is implemented through selection. Materials corresponding to the categories indicated in the collection development policy are identified, individually or en bloc, and decisions then made concerning their possible acquisition. Selection results in decisions to acquire, or not.

(3) Acquisition, finally, is the implementation of selection decisions (Hazen, 1990, 278 - original emphasis).

First, Edelman $(1979,34)$ divided collection development planning into substages which are significant for the selection processes:

(i) Classification of library materials by source;

(ii) Identification of the universe of published knowledge; and

(iii) Development of objectives for short-term demands and long-term needs.

Edelman $(1979,34)$ further divided the selection process into several substages:

(iv) Identification of information resources; 
(v) Evaluation of the quality of the identified information resources; and

(vi) Final review of the selection processes and decision-making regarding the inclusion/exclusion of material in the library's collections.

These various substages were contingent on the four main conditions identified above (Edelman, 1979). Edelman's (1979) model serves a framework of analysis for my research. It is reflected in the following discussion on map librarianship, the research objectives and questions, and the overall organisation and structure of my dissertation.

\subsection{The nature of collections}

Library collections indicated that currently library collections potentially comprise of locally and remotely located (physically or virtually) and tangible and intangible (hardcopy and electronic) information resources (Gorman, 1999). Library science literature advocated that information resources should be integrated together into library collections, services and processes regardless of their format (Johnson, 1997) and medium of communication (Budd and Harloe, 1997). An emphasis on the information content of information resources emerged in library science, with a concomitant paradigmatic shift away from the format of resources (Budd and Harloe, 1997; Dorner, 2000). Cartographic literature also endorsed such an emphasis, although with the caveat that different types of cartographic materials had different capacities for user interaction. Current map library practice, however, tended to indicate that many map libraries still preferred to select hardcopy maps over digital cartographic materials, especially geographic information system resources (Perkins and Parry, 2001).

Bühler $(1999,228)$ stated that "a modern map collection had to offer both traditional and digital materials". He gave an overview of the variety of electronic cartographic materials that could be made available through map libraries, and various software and hardware configurations that could be used to provide such materials. His own library collection boasted full range of cartographic materials, including statistical data "with geographical reference" (Bühler, 1999, 228).

Parry (1995) proposed two options for the development of map library collections. The first option was that they could remain essentially the same developing collections that continue to have static cartographic materials at the core of their collections. GIS laboratories were left to provide access to interactive and dynamic cartographic 
materials. In the second option, map libraries could adopt a 'radical approach', whereby they could provide access to a full range of electronic cartographic materials in addition to the traditional materials. Perkins (1995) proposed an additional two options. Option three would be that libraries could collaborate with GIS laboratories or spatial data providers in providing not just access to electronic cartographic resources but also interpretive and analytical services to users. Expertise in electronic cartographic materials, especially GIS would have to be developed in the library as well as the GIS providers. Both institutions would also collaborate in acquiring spatial data. Option four would be where libraries continued to provide a conventional map library service in tandem with providing PCs in their building for network access to electronic cartographic materials, which the GIS laboratory would continue to manage. In this model, no attempt would be made to integrate conventional and electronic materials into an "integrated system" (Perkins, 1995, 321).

In his review of reports on the availability of digital cartographic materials through map libraries, Perkins (1994) found that few map libraries in North America and the United Kingdom had moved beyond providing users access to hardcopy maps. The most progressive map libraries tended to be associated with institutions that used "GIS for teaching", but even in those institutions the provision of access to dynamic digital cartographic materials "are often not offered as part of the map library" (Perkins, 1994, 4). The mix of traditional and electronic cartographic materials that comprise a collection depended not only on the availability of electronic materials, but also on external and internal pressures (Millea, 2001).

McGlamery (2001) indicated that the libraries more likely to develop geographic information systems services have staff who have skills and experience with these products, or have the resources to employ specialist staff. Alford (2000) indicated that ensuring that all selection staff have skills in, and experience of, using electronic resources leads to better integration of hardcopy and digital information resources than establishing specialist positions for electronic resources librarians, leaving other staff to deal with other formats. The process of selecting cartographic materials has become more complicated because it requires skills to seek and identify, evaluate and provide access not only to maps and other conventional cartographic materials for their services, but also to a range of digital cartographic materials which they provide access to in a number of different ways. 


\subsection{Identification of new cartographic materials}

Changes in cartography and mapping have had an impact on the identification of new cartographic materials. Fundamental parameters that define cartographic materials have been redefined. For instance, the shift in defining the products of cartography from objects to subject matter raises questions such as what defines a publication (Fairbairn, 1993). Fairbairn $(1993,62)$ suggests that "the concept of 'sheetlines' becomes redundant in a seamless digital database covering the entire country [the United Kingdom]".

That the development of on demand mapping and automatically updated spatial databases raises concerns about the definition of a new edition. Millea $(2001,32)$ suggested a solution:

Historically, new editions of printed paper maps were published after a certain number of house units of change. The UK legal deposit libraries have moved away from accepting new editions of map sheets every '20 units of change', to an annual digital snapshot of data - the entire database refreshed each year.

In the past, identifying cartographic materials was difficult because of the lack of adequate bibliographic control of cartographic materials, published information about map publishers, and adequate buying aids (Perkins, 1987). In New Zealand, there are no specialist buying guides on New Zealand cartographic materials. New Zealand's national bibliography, journal reviews and the websites of various official and commercial mapping organisations are sources of information about new cartographic materials (Parry and Perkins, 2000).

Perkins (1994) suggested that most standard acquisition tools used by map libraries ignore digital products. In New Zealand, in 2001, that certainly appears to be the case. The scope of these information sources is limited. Many new cartographic materials are not included in the New Zealand National Bibliography, because the National Library has currently not developed procedures for bibliographic control of them, and the supporting technologies have not yet been installed (Small, 2001). Journal reviews (e.g. Datum) are sources of information of significant new cartographic materials, but are unreliable for less significant new cartographic materials and are also published infrequently and cannot review all new available products. Parry and Perkins (2000) indicated that tools for identifying cartographic materials produced overseas are much better developed, including traditional tools such as guides, selection aids, cartographic 
wholesales, library catalogues, and newer tools such as specialist cartographic websites. Websites, in particular, are a good source of information about cartographic materials.

Perkins (1987) argued that the nature of mapping organisations and the overall structure of mapping industries in particular areas influences the access to and identification of cartographic materials. Perkins (1987) suggested that keeping track of changes to mapping organisations is essential to keeping up-to-date with new publications. The latest restructuring of official mapping agencies and their funding in New Zealand has led to an increase in the number of organisations, both official and commercial, producing cartographic materials (Forer, 2001). Librarians now have to keep track of organisations involved in mapping and also deal with a greater number of organisations. Selectors have also had to adapt to a change in relationship between map libraries and the mapping industry. Over the latter part of the $20^{\text {th }}$ century, the industry became more complex reflecting "the broader nature of the industry" (Forer, 2001, 192). At the turn of the twentieth century, selectors not only had to deal with a greater number of mapping organisations, but also a more commercial relationship (Forer, 2001).

\subsection{Evaluation}

Davis (1997) outlined how traditional evaluation criteria should be expanded to meet information needs in an electronic environment. The three traditional criteria are the reputation of the author and publisher, the scope and breadth of content, and the relevant details of special formats or features. In evaluating electronic resources, Davis (1997) suggested two other fundamental criteria, namely technological options and licensing issues to both the information content and the software platforms. Forer (1993) also emphasised concerns about intellectual property rights to baseline spatial data, although in New Zealand the intellectual property right restrictions have essentially been removed from officially produced baseline data (Forer, 2001).

There are some essential qualities of digital cartographic information that affect their availability and usage. In his review of guides to evaluating traditional and digital information sources, Smith (1997) emphasised traditional criteria such as scope, authenticity, accuracy of information resources, but also placed strong emphasis on their ease of use. Perkins (2001) highlighted speed of use, which particularly relates to 
downloading from the Internet, and library facilities and resourcing concerns such as hardware and software compatibility with existing resources.

Somehow, each library needs to work out some kind of formula for calculating the costs of the technical characteristics of each information resource. In a survey of libraries' use of traditional criteria and emerging criteria (much like the technical criteria discussed above), Norman (1997) found that libraries were more likely to use traditional criteria. Perkins (1993) cautioned against the assumption that providing access to new digital information resources is necessarily the best (most economic or relevant) option. Ultimately, Larsgaard $(1998,7)$ argued that the evaluation is "exercised for digital formats as it is for hardcopy formats" in that the overall quality of an item should be judged "by its source's reputation and by reviews" and according to its relevance to user information requirements. Given the specialist nature of cartographic materials, there are additional specialist evaluation criteria that need to be considered. Demas (1989) divided selection criteria into primary and format-specific criteria. The primary selection criteria, for instance subject relevance, intellectual content, reputation of author, remain constant regardless of format. However, with each new format (and access mechanism), "unique considerations are introduced" (Demas, 1989, 230).

\subsection{Selection decision making}

The increased range and number of cartographic materials gives map librarians much greater choice of products, and potentially enable them to cater for a greater range of user information needs. At the same time, however, the choice of products and their means of delivery can be bewildering (Larsgaard, 1998). There is also a greater rate of obsolescence of cartographic materials in the current mapping environment, especially hardcopy cartographic materials (Parry and Perkins, 2000). This suggests that librarians will therefore have to have up-to-the-minute information about new resources. While this is a task that they have always undertaken, with the rapid changes in technology and cartographic practices, they will probably have to look increasingly for assistance or advice from external experts, especially from subject (Larsgaard, 1998) and technology (McGlamery, 2001) specialists. 


\subsection{Conclusion}

The overall role of map libraries has essentially remained the same, that is to provide users with access to geographic information resources. The nature of published geographic information resources available in New Zealand and methods of publication are changing. Rather than an emphasis on the container of the information resources, more emphasis is being placed on the intellectual content of the resources. There are a number of issues that have been raised in this literature review which affect the identification, evaluation and selection of spatial data and cartographic materials for map libraries in New Zealand. These include:

- Functional changes and renaming of agencies;

- Changes in funding of official mapping;

- Increase in the number of official, non-official and commercial organisations producing cartographic materials;

- Increase in the number and types of cartographic materials; and

- Need to consider essential administrative or management issues such as intellectual property rights and the use of mediating technologies.

The literature suggests that libraries have had to develop a range of strategies to their selection practices such as developing new tools and methods for identifying items, developing additional criteria for evaluating items, and developing additional processes for final decision-making about items. It also indicates that there is little research on the impact that changes to cartography and mapping agencies have had on the selection of cartographic materials for libraries. 


\section{RESEARCH METHODS}

\subsection{Introduction}

It is my intention in this research to describe the kind of work that the interviewees, as selectors of cartographic materials, do, and the various ways their work has been impinged upon and changed in response to changes in related technologies and techniques and methods of storing, conveying and analysing spatial data and information. As outlined above (in 2.13 A theoretical model of selection practices, p.18), Edelman's (1979) model of the selection process attempted to provide an understanding of the concepts and activities involved in selection. Using his model, I have attempted to research how different elements of change in cartography and mapping have affected the process of selecting cartographic materials.

This chapter outlines research objectives and questions that adhere to Edelman's (1979) model. It also describes research methods that I argue are appropriate for this project given the kind of data that I require to meet the research objectives and given the overall nature of the research project.

\subsection{Research objectives}

Considering the research goal in terms of the different components of the process of selection, I developed five research objectives. They were to:

(1) Describe from the point of view of the interviewees factors that might affect their selection practices that have been the result of changes in cartography and mapping;

(2) Describe the current scope of specialist map libraries in New Zealand and how the scopes of the libraries have changed in the context of changes to cartography and mapping in New Zealand;

(3) Describe the means and tools specialist map libraries in New Zealand currently use to identify cartographic materials and sources of maps and cartographic materials; 
(4) Describe the impact of changes in cartography and mapping in New Zealand on the approaches of specialist map libraries in New Zealand to evaluating cartographic materials and sources of cartographic materials;

(5) Describe the impact of changes in cartography and mapping in New Zealand on the selection decisions specialist map libraries in New Zealand.

\subsection{Research questions}

In order to meet the above research objectives and to develop research approach and strategy, I asked myself the following questions about the process of selection of cartographic materials.

\section{Collection development (planning)}

1) What elements of changes in cartography and mapping affect the libraries' selection practices?

2) What is the nature and scope of the map libraries' collections?

3) What are the long-term visions of the map librarians for collections, and how have they responded to changes in cartography and mapping in New Zealand?

4) Do the map libraries provide digital cartographic materials? If so, what kind of resources and access to resources are they providing?

\section{Selection processes - identification}

5) How do the libraries identify New Zealand cartographic materials for their collections? What sources of information about products do they use, how do the libraries identify them?

6) How, if at all, have these practices changed in the context of changes to mapping in New Zealand?

\section{Selection processes - evaluation}

7) How do the libraries evaluate cartographic materials for their collections? Do they use a formal list of criteria and what criteria do they use?

8) How, if at all, have these practices changed in the context of changes to mapping in New Zealand?

\section{Selection processes - final selection decision making}

9) How are the final selection decisions made, and by whom?

10) How, if at all, have these practices changed in the context of changes to mapping in New Zealand? 


\subsection{Research approach}

My research was guided by literature on selection processes, in conjunction with semi-structured interviews. The research was an exploratory study and needed to probe indepth into the practices of a few respondents, rather than a large number. The literature suggests that library selectors use both institutional policies and their own personal knowledge, skills and experience to identify, evaluate and make a decision whether to select materials for their collections (Norman, 1997). As special libraries, map librarians tend to be involved in many areas of librarianship, planning, selecting, and providing user and reference services (Larsgaard, 1998). Hearing from the selectors what approaches and techniques they develop and use is the best approach to investigating the effects of changes in cartography and mapping on the selection processes used in map libraries.

\subsection{Interviewing}

In light of these research conditions, a research methodology that is exploratory in nature and permits data to be gleaned directly from the selectors is appropriate. The kind of data required in order to develop an understanding of the selection practices are general and specific principles, strategies and practices used by the respondents. Interviewing as a method of investigation suits both exploratory research and researching a small group of respondents (Singleton, Straits and Straits, 1993). Gorman and Clayton (1997, 44-45) wrote that "interviewing can obtain detailed, in-depth information from subjects who know a great deal about their personal perceptions of events, processes and environments". Semi-structured interviews were chosen as the most appropriate methods of gathering data given my circumstances and the kind of data I required.

An interview guide (see Appendix one: Areas of questioning, p. 70) provided the 'semi-structure' to the interviews (Patton, 1980) and some constancy in the data gathered from the research respondents (Singleton et al., 1995). A list of the areas of questioning was sent to the respondents before the interviews, but the exact wording of the interview questions was spontaneous (Gorman and Clayton, 1997). This approach "enables the interview to be more natural and conversational" and made it "easier for the interviewer to respond to points made by the interviewee, and to gather quite 
detailed, comprehensive data" (Gorman and Clayton, 1997, 126). In turn, this permitted a degree of aggregation and comparison between respondents and an insight into possible trends. In addition to the interview guide, some further questions were asked to assist in probing a subject or issue.

Because of limited personal financial resources and because my family life at the moment does not permit travelling to each centre, all participants, including those in Wellington, were interviewed by telephone. Participants were also asked to provide copies of their selection policies, evaluation criteria and information sheets about the library, its collection and services.

\subsection{Sampling}

Two groups of people participated in this research:

1) Specialist map librarians of the Universities of Otago, Canterbury, Auckland, Waikato and of the National Library; and

2) Managers or technicians of GIS laboratories.

Participants were sent an email about the research. The email contained a letter of introduction, details of areas of questioning and a consent form. All five interviewees responded relatively quickly with an email agreeing to participate. I made a follow-up phone call several days later to organise a time for an interview, to ask their permission to record the interview, and to ask if they had any questions or comments at that stage. One interviewee was unable to participate in the research.

\subsection{Stages of data analysis}

I adopted a reflexive writing approach to data analysis (Rice-Lively, 1997). The interviews were recorded and I took notes during the interviews. Rather than transcribing the interviews verbatim, I listened to each interview twice, selecting and transcribing only data that I considered relevant to the framework of analysis. Then reread the transcriptions several times, as suggested by Rice-Lively (1997). Through repeated listening, selecting and typing quotations, and always bearing in mind the framework of analysis, I was able to "focus my attention in new ways", and gain "fresh insights and revelations" from the data (Rice-Lively, 1997, 203). 
I chose not to transcribe the interviews in order to save time. I still wanted to record the interviews so that I could use verbatim quotations to discuss the themes in the 'words of the interviewees'. The verbatim quotations allowed me to get overall impressions of the selection practices and insights into specific details of the selection practices. They were also used to discuss the influences of changes in cartography and mapping on the selection practices and the selectors' adoption of specific approaches, techniques and tools. The interview notes served as rough indices/guides to the data in each interview and as a back-up in case the recordings were incomprehensible. Taking notes during the interviews permitted me to follow the interview better, to develop additional questions during the interview (probing).

After the interviews were conducted, I replayed the tapes, and, following the framework of analysis (outlined above) and the areas of questioning, I developed preliminary 'rough' themes, which I typed in the first column of a table (see example of table overleaf). Some of these rough themes later became major elements in my data analysis. When quotations from the interviewees related to the preliminary themes, I entered them as data in the corresponding row. Each of the quotations from the five interviewees are separated into different columns in tables.

Listening to the tapes again, I then identified different themes and typed the corresponding quotations into the table under the major elements. Once completed, I read the text in the tables, identifying, highlighting and coding secondary themes, which were either sub-themes that stood on their own or corresponded to other main themes. In this way, connections were at times made between main possible influences and possible effects, and I was able to confirm, sort and sift patterns and main and secondary themes that emerged (Rice-Lively, 1997).

I read collection policies and other information brochures about the participating libraries for relevant information. One library did not have a collection policy, although its website did have some outlines of parameters of its collection for the public. I read and re-read the emails from the GIS Managers/Technicians for data that corresponded to the framework of analysis and questions that arose from the interviews with the map librarians about interaction of libraries and GIS laboratories. 
Table One: Example of table of analysis (table of changes to mapping by quotations about restructuring of mapping organisations)

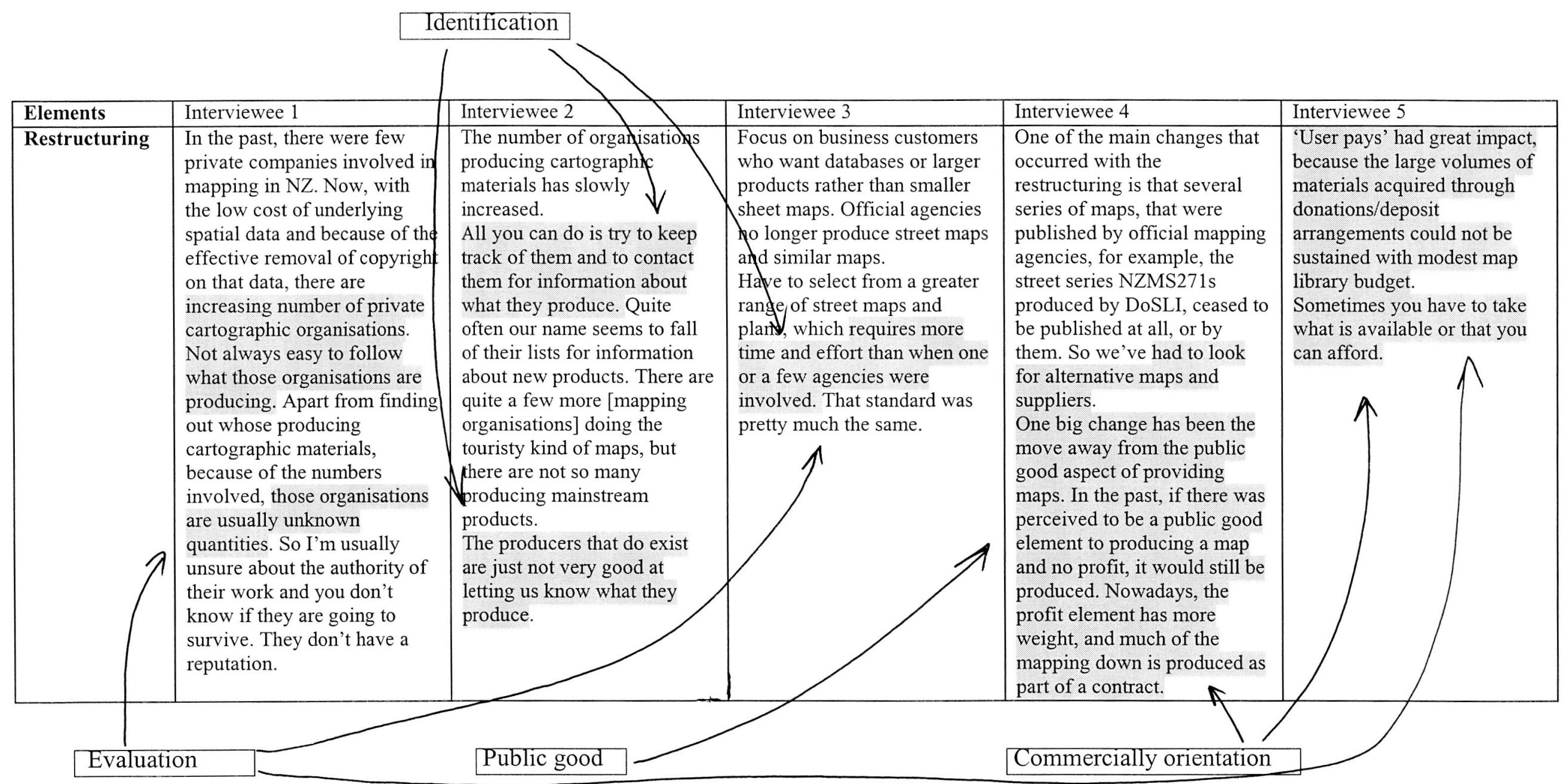

Highlighted text were sub-themes that stood on their own or corresponded with other main themes. Terms for the sub-themes, in this example of a table, are in small dialogue boxes. 


\subsection{Ethical considerations and presentation of interviewee data}

The Victoria University Human Ethics Committee assessed the research project and indicated that the research project meets its guidelines. In order to preserve the confidentiality of the Interviewees, I took the following precautions in the presentation of data in the dissertation.

Data were presented using either paraphrasing or actual verbatim quotations which could not be attributed to any one of the five interviewees. Instead of attributing verbatim quotations or paraphrases to interviewees using their names or job titles, I used the term interviewee and a number to refer to different interviewees.

\subsection{Conclusion}

In this chapter, I outlined my research approach. I suggested that semi-structured interviews offer a research method that provides the kind of data that is relevant to the exploratory nature of the research project and that provides the depth of quality of data that is needed given the small number of research participants. I also outlined my research objectives and questions which I formulated from Edelman's (1979) model of selection practices. In the next four chapters I present my research findings in a narrative form. This form closely follows the development of my thinking along the research path as I read and re-read the interview data and made connections between them and literature on map librarianship. 


\section{CHANGES IN CARTOGRAPHY AND MAPPING - PERSPECTIVES OF MAP LIBRARIANS}

\subsection{Introduction}

Changes in cartography and mapping in New Zealand, and indeed in the western world, have occurred rapidly in the last couple of decades, as is evident in the literature review. The literature review introduced some of the changes that have occurred in cartography and mapping in New Zealand. In this chapter, I sought to meet the first objective, that is to:

Describe from the point of view of the interviewees factors that might affect their selection practices that have been the result of changes in cartography and mapping.

\subsection{Changes in cartography and mapping}

The main change identified by the interviewees was the emergence of digital cartographic materials, and that nowadays most map publishers (paper and digital), if not all, work from electronic databases of spatial data. Interviewees point out that while the advances in the use of computer and information technology have enabled the publication of digital cartographic materials, they have also affected the publication of traditional maps. Some of the advantages of digital cartographic materials were discussed such as the capabilities to manipulate and visualise spatial information, multimedia capabilities, on-demand production of output of cartographic items, and the greater range of the products being made available.

Many maps and images that only used to be available in paper form are now also more conveniently packaged in electronic form, and output could be produced ondemand and according to user specifications, according to Interview One. For example, 
Interviewee One talked about electronic cartographic materials which usually do not have sheetlines so that a user-selected indexed geographic feature in such a product would usually appear at the centre of the output; there is no need to bother with aligning geographic features on the periphery. Interviewee Five alluded to "flexibility" of electronic cartographic materials which permitted some digital cartographic materials to produce map output on a monitor that can be enlarged or reduced (zooming).

At the time of the interview, the interviewees were concerned with how cartographic materials now have, what Interviewee Four termed, a more "ephemeral nature". When discussing the effect of new cartographic technologies on hardcopy maps, Interviewee Three sceptically suggested that "while topographic maps are being printed more often, you wonder whether they are actually being updated". Interviewee Two thought that "less printed maps in any one print run and less map series are going to be produced". The implication was that purchasing particular map sheets will probably become difficult. Interviewee One thought that "it will become difficult to purchase one map sheet, instead you will have to buy a product that covers a more extensive area". Interviewee Four indicated that digital cartographic materials were, especially if they are accessed via the Internet, often continually updated so that it was "difficult to keep track of the updates".

One of the capabilities that sets digital cartographic materials apart from traditional hardcopy products is their more or less momentary transportability via the Internet. The emergence of the Internet and web cartography has led to ever increasing use of the Internet to publish cartographic data and information.

There is a lot of material being mounted on the web and by a wider range of agencies and a lot of local cartographic and related materials being placed on the web (e.g., aerial photographs) (Interviewee One).

Interviewee Two believed that this capacity will lead to less "physical library collections" and that "a network of libraries will probably develop". He was mainly positive about these development and suggested that "while some users will probably by-pass the library", libraries will develop their "own specialist materials". Indeed, Interview Three spoke about how an Intranet network within the larger institution that his library was located in permits his library to gain:

Access via distributed network to products owned by another department of the larger institution, although there were licensing restrictions which limited the number of users at any one time. 
Furthermore, using electronic cartographic materials that are Intranet capable enabled several map libraries to combine with other departments within their institutions to purchase expensive software and spatial data products, thereby sharing the costs of acquisition.

\subsection{Nature of changes to mapping}

The Interviewees raised two main topics during the interviews regarding changes to mapping in New Zealand, namely the restructuring of mapping agencies and increasingly commercial models in mapping. New Zealand's official mapping agencies were restructured and the relevant Acts of parliament were amended during the 1990s. Interviewees spoke about the division of DoSLI (Department of Survey and Land Information, NZ) into separate organisations that fulfilled separate functions. As part of the restructuring, Interviewee Five discussed, among other structural changes to the organisations, the centralisation of district LINZ (Land Information New Zealand) offices. For example, collections ${ }^{5}$ of cartographic materials previously held at the Dunedin District Office were moved to the Christchurch Regional Office. In addition to structural changes, and perhaps more significantly, changes in the overall ethic of official mapping agencies were singled out by interviewees. One of the most fundamental of changes occurred during the restructuring:

There has been a move away from the public good aspect of providing maps. In the past, if there was perceived to be a public good element to producing a map and no profit, it would still he nroduced. Nowadavs, the profit element has more weight. Few of those maps end up in the public domain at all (Interviewee Four).

Furthermore, Interviewee Four indicated that official mapping agencies also moved away from the publication of some map series:

One of the main changes that occurred with the restructuring is that several series of maps that were published by government mapping organisations, ceased to be published at all, or by them, for example, the street series NZMS271s produced by DoSLI.

Cadastral or land information required for the transfer of title of lands which previously was administered through the LINZ offices, including district offices, is now acquired via the Internet. 
The effect of the change in ethic not only extended to the production of maps and cartographic materials, but also to their distribution. Prior to the restructuring, most of the map libraries had a depository arrangement with official mapping agencies. However, a "user pays" approach was implemented that:

Had a great impact because the large volumes of material acquired through donations/deposit, arrangements could not be sustained with modest map library budgets (Interviewee Five).

Such map library deposit arrangements would have been possible under the original large print runs of official mapping agencies and the systematic approach to mapping.

Concerns were also expressed about the nature of digital cartographic materials, and not only static but also interactive products:

Some electronic products are not really archival material. It appears as though newer data just wipes out the previous data so there is no historical record (Interviewee Three).

The usefulness of the data on the databases, and therefore the databases is questionable, because they [spatial databases] are constantly being updated (Interview Four).

Interactive cartography was seen as not being a "final product" in the same sense as specific editions of paper maps, yet in some cases electronic products were replacing traditional hardcopy editions. A specific example cited by Interviewee Four was cadastral mapping of New Zealand which was now an Internet-based, user-pays, ondemand cartographic product. Previously, a paper map series was available for map libraries to purchase, and as a series this indicated changes over time. This is illustrative of why some interviewees are reserved about accepting, at least wholesale, digital interactive and dynamic spatial databases, especially those available over the Internet. A solution suggested by Interviewee Three was that paper copies of such databases could be taken, presumably at a regular interval.

Another result of the increase in commercial mapping organisation and of a commercial emphasis in official mapping agencies, is a market-driven approach to the publication of cartographic materials emerged. Specific markets were now identified and targeted for certain cartographic materials before they are produced: 
Much of the mapping done now is produced as part of a contract. The finished map will be produced for a particular company or individual and for a particular purpose (Interviewee Four).

This approach was implemented as part of the requirement for official mapping agencies to operate on a for-profit basis. Although LINZ no longer operates on a forprofit basis, interviewees suggested that a market-oriented product development strategy still continues today and affects the selection of cartographic materials for map collections.

Interviewees also suggested that the increased availability of underlying topographic data from LINZ had led to an increasing number official and commercial organisations becoming involved in producing cartographic materials. For instance,

What has changed has been the involvement of some larger map shops in publishing their own digital cartographic materials (e.g., Map shop's Topomap 2.0). (Interviewee One)

\subsection{Conclusion}

This chapter described from the point of view of the interviewees factors that affected their selection practices that have been the result of changes in cartography and mapping. Two main changes were described. Firstly, the emergence of electronic cartographic materials has led to spatial information being conveyed in a greater variety of formats and media. Secondly, in the current climate, the mapping industry is much more market-oriented: cartographic materials are produced for specific markets and the number of mapping organisations, both official and private-sector, is increasing.

The interviewees raised several concerns about how these changes had had impacts on the selection of cartographic materials for their collections. How those impacts have manifested themselves in map library selection practices is topic of the next three chapters. The next chapter focuses on map libraries' collection policies, their nature and scope, and possible future directions. 


\section{COLLECTION POLICIES}

\subsection{Introduction}

The previous chapter discussed interviewees' views on changes in cartography and mapping that have influenced their selection practices. This chapter aims to:

Describe the current scope of specialist map libraries in New Zealand and how the scopes of the libraries have changed in the context of changes to cartography and mapping in New Zealand.

\subsection{Collection development policy and electronic materials}

Four of the five map libraries had written collection development policies. Three policies were essentially out-of-date in terms of stating that the libraries collect a range of formats (including electronic formats). Three policies had been written or last amended in the late 1980s or early 1990s. For instance, one collection policy was thirteen years old:

Our collection policy is thirteen years old. I am currently updating it. It is a working document, but out-of-date. It does not mention electronic materials at all.

The other policy was written in 1999. Two policies had statements that included the collection of electronic materials of any kind, for instance:

The collection policy... should allow for the acquisition of differing forms of cartographic materials (maps, charts, ... computer produced maps...).

The policy written in 1999 anticipates the need to collect electronic cartographic materials by signalling the need to identify and recommend new electronic resources for future purchasing when the library was in a position to provide for those formats. The 
fifth map library did not have a written collection development policy. Instead, according to the Interviewee, it had a high level "statement to say what is the role of the library and whose information needs are to be met". This had permitted a certain amount of flexibility in selecting materials for the collection at the same time as keeping in touch with "the changing user information needs and the changes in formats". Indeed, the other interviewees indicated that a degree of interpretation of the policies was required when identifying and evaluating materials for their collections during the dayto-day library operations. In the interviews, the librarians suggested that collections now had to provide user access to information resources in a variety of formats, but still work within the subject scope of the collection development policy.

\subsection{Nature and scope of the map libraries' collections}

Three of the five interviewees were university map librarians. In broad terms, the main purposes of all of the map libraries were to support the teaching and research activities of their constituent staff and students, and secondarily to meet the information needs of their local community. The other map libraries were more collection focused, aiming to collect, preserve and provide access to current and historical cartographic information that included comprehensive or advance research-level coverage in their particular areas of speciality.

All of the map libraries had geographic emphasis on New Zealand, the Pacific Islands (especially those that have direct relations with, or are in close proximity to New Zealand), and Antarctica. They sought to collect comprehensively (or at an advanced research level) both topographic and thematic cartographic materials in those geographic areas and at a range of scales (large-, medium- and small-scale). One map library sought to collect comprehensively all historic maps (ie. including both topographic and thematic, and a range of scales) in those geographic areas, but its current collection was limited to topographic materials only. Because of specific research interests within their local research community, some map libraries also collected comprehensively in other geographic areas outside those already mentioned. The interviewees also indicated that generally their collections of overseas cartographic materials were declining, which reflected both declining user research interests in those areas, changes in depository arrangements with overseas mapping agencies, and the 
need to narrow their collection scope because of reducing or re-targeting of budgets priorities.

\subsection{Future direction - digital mapping and online access to existing maps}

All five map librarians not only intended to develop the collection of electronic cartographic materials, but also had already begun to collect a range of electronic cartographic materials. The interviewees generally expressed long-term visions that electronic cartographic materials will become increasingly significant in their collections:

The library will make use of online access to existing maps and mapping packages that permit the user to produce their own maps (Interviewee Two).

At the same as being acquiescent about collecting or providing access to electronic cartographic materials, some expressed a range of issues and concerns. Interviewee Three expressed a feeling of inevitability about the need to collect electronic materials because some spatial information will over time no-longer be purchasable in hardcopy format:

I tend to bury my head in the sand when it comes to digital information at the moment, because our users do not really want such material - but I guess it will come if that is all that is available.

While Interviewee Five believed his library's map collection would become increasingly digital, his view was tempered with concerns about the difficulties of ensuring future access to digital spatial data and information because of the volatility of electronic information resources:

We might print off hardcopies of some images or maps from some databases or websites, because the data and images tend to be replaced without archiving them.

The expense of the acquiring spatial data and information was also a concern voiced by interviewees. Some interviewees believed that, as map libraries were having to cope with declining budgets, gaps may develop in their collections, or the scope of their collections may have to be reduced: 
Because digital products are so expensive, we may well start developing significant gaps in our collection, simply because we cannot source a hardcopy and the digital version is too expensive for us (Interviewee One).

According to Interviewee Five, the greater availability of digital cartographic materials was a potential threat to the future of map libraries as a separate entity, staffed by a specialist map librarian:

That mapping products can increasingly be accessed over the network and that the library's usage statistics are decreasing are the main reasons that the library's future is uncertain. It probably depends a lot on the proportion of hardcopy materials and electronic materials available through the web. Pretty sure that it is safe for at least the next five years.

The interviewees raised one other final issue. Some suggested that their lack of specialist skills for using some electronic cartographic materials was an impediment to the introduction of more electronic resources:

I am happy to purchase digital material. My feeling is, however, that I do not have the technical know-how to get the best [out of the resources] once we have got it (Interviewee Four).

Apart from the need for additional staff training and development, interviewees highlighted some practices that assisted with overcoming some of the technical barriers, for example partnerships with other departments or institutions to provide access to materials:

I am pleased that we have got this partnership with the geography department so I can rely on their expertise to help develop that section of the collection on campus (Interviewee Four).

Notwithstanding the issues and concerns that the map librarians raised, all five map libraries provided users with access to electronic cartographic materials. When exploring the digital future of their collections, some interviewees discussed developing cooperative purchasing or resource-sharing arrangements with other departments located within the same larger institution (e.g., Geography Department, or other library branches) as an option for better resourcing of electronic cartographic information and services:

This year we just got access to medium-level GIS package so that I can produce maps on-demand from the Landcover database without having to 
continue to bother the GIS technician. We are looking to have more integration between the library and the lab (Interviewee One).

Indeed, Interviewee Four detailed a joint geography department and map library project. Its objective was to develop a virtual map library and spatial data collection on campus to complement the printed map holdings held in the current map library (Project Steering Committee, 2001). The resources will be distributed via the web, and will comprise "national digital data coverage of all topographic maps, major administrative and census boundaries, land capability surveys and land classification records, scanned versions of all the printed topographic maps, national data sets on Maori land, and rich coverage of local area spatial data" (Project Steering Committee, 2001, p. 1). The Project Steering Committee (2001, p. 1) argued that such projects were needed to "create an 'environmental memory".

\subsection{Collection of electronic cartographic materials}

All five had electronic materials in their collections. One library provided access to much fewer electronic cartographic resources than the other five map libraries, although, as mentioned above, the librarian also expected that this would change as more electronic publications were published and became more accepted or in demand by library users. Before considering some of the methods of access to the materials, I will discuss what distinguishes the materials from those found in GIS laboratories.

The materials that the libraries tended to provide access to were termed "finished products" as opposed to the "underlying data" (Interviewee One) that GIS laboratories provide access to. Interviewee Five distinguished the library collections from the local GIS laboratory's in a similar manner, stating that the GIS laboratory provided "unprocessed datasets which users have to manipulate". The GIS laboratory managers who were contacted had similar views, and added that some or all of the cartographic qualities (discussed in the literature review, p. 12) have been applied to the materials in libraries:

Our GIS spatial data tends to be vector based with associated database tables, rather than being finished cartographic material, so the user [of the data that we provide] has to apply symbolisation and other map elements (GIS Manager Two). 
The data used in the GIS laboratories also tended to be purchased from agencies that are directly involved in capturing spatial data, and creating and maintaining databases of raw spatial data. The map libraries by contrast tended to select cartographic materials that were published by an agency or organisation that added-value to the original raw data. Therefore, in the words of Interviewee Four, map libraries were "mainly focusing on mainstream paper and digital products".

The kinds of materials that they included in their collections were of a range of different formats, among others, on CD-Rom, loaded on local personal computers and accessed through local-area networks (the larger institutions' Intranets), and via world wide web.

The majority of the electronic cartographic materials held by the map libraries was in CD-Rom format. While some libraries held fifty or more CD-Roms, others only held a handful. A range of types of cartographic information resources were purchased in CD-Rom format such as "street maps, topographic maps, and satellite images" (Interviewee One).

Two map libraries mentioned involvement in digitising or scanning previously published and manuscript paper maps that were in their collections. Interviewee Five's map library had:

Just instigated a project to digitise 250 old maps of historically interesting material and significant for this region, the local towns and region, and that are out of copyright.

Furthermore, the purpose of the project was to help conserve the originals and provide greater distribution of valuable local maps. The digitised maps will be made accessible via the Internet.

The map libraries provided users with access to cartographic information resources available via the Internet and via their local Intranet. The Internet materials were cartographic materials that they had identified and added hyperlinks to on their web pages. Included in the Intranet materials were a range of static and interactive electronic cartographic materials. Among the links that libraries had to websites were "Pipers maps" and Land Information New Zealand's Internet based resources such as cadastral information, and gazetteer.

Some map libraries, located within larger institutions which also had GIS laboratories, had direct arrangements with such facilities to assist in providing users with electronic cartographic materials via their Intranet. Some initiatives to provide 
users with on-demand mapping were being negotiated between libraries and geography departments:

The library has a terminal that links up to the Geography Department. The terminal has ARCView, a GIS system, that allows us to draw maps of New Zealand. The Geography Department do the data selection. The terminal is also used for the CD-Roms. I have got a bit of experience using the computer and the software, but usually the users help themselves (Interviewee Five).

Map libraries were also cooperating with other departments to provide users with greater access to electronic resources, which would otherwise purchase, or lease. For example, one library had recently negotiated with another university department to purchase a campus-wide site license for a particular electronic cartographic item, instead of just a single-user license.

\subsection{Conclusion}

This chapter sought to describe the current scope of some specialist map libraries in New Zealand and how their scopes have changed in the context of changes to cartography and mapping in New Zealand. Overall, collection development policies of the map libraries were not specifically inclusive of electronic materials, although the libraries had begun to provide access to electronic materials. The majority of cartographic materials were static cartographic materials such as paper maps and digital databases of (static) images of maps and satellite images etc. Dynamic databases of spatial data and information (e.g., geographical information systems) have largely been left to the development of GIS laboratories. One option that one or two libraries had chosen was to arrange to have a personal computer networked with the local GIS laboratory in order to gain access to locally held spatial data and information. The main purpose of these personal computers was to produce maps on-demand, and not to undertake analysis of spatial information. The next chapter examines the effect of the changes in cartography and mapping on the identification of new cartographic materials for the libraries' collections. 


\section{IDENTIFICATION PROCESS OF \\ CARTOGRAPHIC MATERIALS}

\subsection{Introduction}

In chapter five, it is clear that the increasing use of information and communications technology in mapping had some influence the librarians' visions of the future of their collections and to a lesser extent the actual nature of cartographic materials being selected for their collections. The aim of this chapter is to:

Describe the means and tools specialist map libraries in New Zealand currently use to identify cartographic materials and sources of maps and cartographic materials.

\subsection{Identification of sources of cartographic materials}

The publishing process has become increasingly fragmented since commercial operating models were adopted by official mapping agencies. Different organisations have been used for different functions in the production, publication and distribution process:

In the early days of the split of DoSLI, there was a problem of some maps falling through the cracks. For example, we used to get park maps indirectly from DoSLI. Next thing was that they were no-longer appearing in the National Bibliography. LINZ sold the rights to producing them to DoC, and now another private organisation markets them. They weren't reporting them to the National Bibliography. There were problems like that - the fragmentation of the production from the supply of maps (Interviewee One).

Interviewee Two highlighted how the fragmentation of the publishing process has affected the identification of sources of cartographic materials and the products themselves: 
It is harder to keep track of what was being produced. Instead of one organisation, there are now four organisations involved. Initially, you could easily go from one [organisation] to the other and so on chasing the a supplier. Things are now settling down. The roles are getting clearer.

Evidently, there are more organisations involved in the publishing and supplying of cartographic materials. While the fragmentation of these processes may account for some of the increased number, this may also be attributable to the change in government policy towards reducing charges for the underlying spatial data:

Now, with the low cost of underlying spatial data and because of the effective removal of copyright on that data, there are increasing numbers of private cartographic organisations (Interviewee One).

As a result, there are greater opportunities available for organisations to produce cartographic materials than was possible under the previous regime of charging for profit for the underlying spatial data produced by government agencies.

\subsection{Information about editions and versions of cartographic materials}

Mapping agencies supplied less information about their new publications than previously, and selectors observed that it was more difficult to locate information editions and versions of maps and cartographic materials, whether they be digital or hardcopy. Dates of publication and of corrections or revisions and statements of editions were essential for providing collections at research or advanced level, which all the map libraries were. For example, few details about cartographic materials were provided on websites that advertise them, or in the few publications that list cartographic materials:

Often they do not have edition statements on them. Sometimes they do, but not that often. It is very hard to keep track of editions. Sometimes they have new titles and ISBNs, but they do not give edition statements or any indication of the changes (Interviewee Two).

Interviewee Two indicated that seeking information about the editions of maps (paper or electronic) was now more time intensive:

The only way of keeping track of editions nowadays seems to be by physical inspection of maps and comparing them to maps that we already own. 


\subsection{Tools for the identification of cartographic materials}

Few tools were available to map librarians to assist in selecting materials published in or about New Zealand, or by New Zealanders, and there was nothing that has systematic coverage of newly available cartographic materials. The interviewees identified the New Zealand national bibliography and the Te Puna union catalogue as the two main tools for identifying maps. Only one directory was identified as providing information about sources of cartographic materials. In addition to those few tools, the interviewees use an extensive range of tools or sources to identify potential sources of information about new cartographic materials and to identify cartographic materials themselves. Developments in communication and information technology have of course also furnished new tools and methods for identifying new cartographic materials.

\subsubsection{National bibliography and other bibliographies}

The main tool used by the Interviewees to identify new maps was the New Zealand national bibliography, which is published electronically on the National Library website.

Interviewee Four thought that:

Nowadays, identifying material is a bit hit and miss. If it does not appear in the NZNB, then there is a good chance that we find out about it.

Bibliographic citations for cartographic materials are interspersed through-out the bibliography, although most appear in the section labelled "Items without Dewey Classification", which Interviewees worked systematically through in order to identify new items for their collections:

I go through the New Zealand national bibliography every month. Now that the bibliography is electronic [available in Microsoft Word document and .pdf formats], it can be searched for 'map' [or 'cartographic material' AACR2r 2001 amendments] using the find [function]. It is especially useful to get details of new editions of maps. That is the main source of information I use for New Zealand maps (Interviewee One).

In addition to the limitations of the national bibliography discussed in the literature review, Interviewees indicated several problems with using the New Zealand national bibliography as a tool for selecting cartographic materials. Interviewees thought there was too much of a delay between the date when maps were released publicly and the 
date of the issue of the national bibliography that records for them appear, especially if the maps are not mainstream publications:

It is not too bad if it is topographic maps, or from major producers such as Wises and Minimaps. What seems to be happening increasingly is that maps, even from government departments are not included in national bibliography until many months down the track and they are no-longer available by the time I get to read the national bibliography (Interviewee Five).

Interviewees suggested that this has been exacerbated by the trend towards publishers only producing small print-runs of maps. Furthermore, Interviewee Two said that only a small number of bibliographic citations of digital cartographic materials seemed to have found their way into the National Bibliography.

Changes in mapping appeared to have lead to less reporting of new New Zealand cartographic materials to the National Library under legal deposit requirements. Any number of factors may have brought this about: the fragmentation of the publication process; no clear understanding as to who should do the reporting; the change in 'public good' ethic; or lack of awareness of staff in the new organisations of legal deposit obligations.

The interviewees were unaware of any other bibliographies of current New Zealand cartographic materials.

\subsubsection{Catalogues}

Some interviewees used catalogues as tools to identify new cartographic materials. Te Puna, the union catalogue of New Zealand libraries kept by the National Library of New Zealand, was the main catalogue used by interviewees:

For map series such as the Topographic Map 260 1:50,000 Series, I would use Te Puna to find out which maps have been recently published and catalogued. I can use Te Puna search module or Webcat. Using the builder search method I would search by series, publisher name and date of publication and all maps in that series published in that year would be brought up in pages of twenty-five entries each. I can then check off these items against our OPAC on-line catalogue and order the ones missing. Its more efficient than the New Zealand national bibliography monthly as it isolates a particular series or maps from a particular publisher. I search series every 6 months and complete an order twice a year if there is no urgency (Interviewee Three). 
The main advantage of using Te Puna was the general level of detail of the bibliographic records. Usually, bibliographic records contained enough detail to enable interviewees to make a clear comparison against there own bibliographic records of maps and their holdings, and to make a clear decision about whether or not to purchase maps.

Some of the difficulties of using Te Puna as a tool for selecting cartographic materials, according to interviewees, was that it does not have a separate facility devoted to searching for cartographic materials. Interviewee Two thought that Te Puna was not able to fulfil its main potential as a selection tool because only a few map libraries contribute bibliographic records and holdings to the database:

In theory, Te Puna provides map libraries with a comprehensive catalogue of New Zealand's cartographic materials, paper and digital. Every institution could provide records of items that they hold. The system is there, however in practice it is not done particularly well. Not all map libraries use Te Puna, or upload their records to Te Puna.

That Te Puna is not a comprehensive catalogue of New Zealand libraries map holdings was reflected by the practice of interviewees searching other library catalogues for gaps in their collections.

\subsubsection{OPACS}

Interviewees also used other New Zealand libraries' on-line catalogues (via the Internet) to identify possible new selections for their map library. There were two instances when they tended to use this approach to identifying cartographic materials. The first instance was when they had heard of or received a recommendation for a possible new acquisition, but did not have enough information to identify the product, or to evaluate whether it met their collection criteria. Interviewee One spoke of a second instance when, during reference inquiries, "you are looking for one thing [information resource] on another library's OPAC and you find another. Serendipity. A lot of serendipity".

\subsubsection{Directories}

Only one directory of current sources of cartographic materials was identified by interviewees as a tool that had a section specifically on sources of cartographic materials in New Zealand. World mapping today $2^{\text {nd }}$ edition, which is written and 
compiled by two British map librarians, has one chapter devoted to explaining changes to New Zealand mapping and highlighting sources of cartographic materials. Although it does highlight some specific products, they are only illustrative of what is possibly available from the sources discussed.

\subsubsection{Internet or web-based tools}

Besides the on-line catalogues discussed above, interviewees used a number of Internet or web-based tools to identify cartographic materials for selection such as websites of organisations and directories, and email/listservices. Interviewees indicated that the Internet was becoming increasingly important for identifying and selecting cartographic materials, especially websites of organisations.

\subsubsection{Email}

Interviewees found electronic list services of little use as sources of information about current New Zealand and Pacific Island materials. "Very occasionally", according to Interviewee Four, "information about the availability of second-hand New Zealand and Pacific maps" was publicised on list services or map library discussion groups, and "only a few maps are bought from this source". List services were mainly useful for overseas cartographic materials. Interviewee Three thought that email was useful to communicate between the close network of map librarians in New Zealand: "we correspond quite regularly", and "sometimes it would be about the availability of cartographic materials."

\subsubsection{Web}

Interviewees adopted two strategies for using the web for searching or browsing for new cartographic materials, or a combination of the strategies. Firstly, similar to Interviewee One's 'serendipity' approach, interviewees also would "trawl around websites" keeping an eye out for new materials. Secondly, interviewees regularly visited websites that they have identified as important sources of information about the availability of cartographic materials. These were usually bookmarked by the interviewees, as Interviewee Three described:

I bookmark specialist sites, which I regularly visit. It's quite new, but it's good, especially for pricing materials. I haven't ordered materials over the Internet but I've looked at prices, and checked publication details and 
looked for reviews. You can more quickly get info about maps than before, that's of course if the information is there.

Two main types of 'specialist' websites were used to identify cartographic materials, namely the websites of organisations and directories, including websites of mapping organisations and suppliers of cartographic materials such as Land Information New Zealand, and Craig Potton. For instance, Interviewee Five regularly visited these sites to find information about new publications:

On a fairly regular basis, I check the news and publication pages of websites of government departments and other mapping agencies for new map titles.

The second kind of websites of organisations interviewees visited were library websites, as discussed above. These sites were not only useful for their on-line catalogues but also for the hyperlinks on their websites to on-line cartographic materials.

Interviewees also used the web to access directories of cartographic materials and mapping organisations (e.g., Oddens Directory), which were entirely overseas-based directories and almost entirely provided information about overseas cartographic publications, hardcopy and digital. One of the main advantages of using the web was that they could get information about cartographic materials quickly and also could often get direct access to on-line cartographic materials.

While websites could be sources of information about cartographic materials, they usually only provided interviewees with brief information about new products that could be used to make further inquiries about materials, but not enough to distinguish those materials from their own holdings, or to evaluate the materials. Interviewee Three thought that "the websites of mapping organisations are rather superficial", or, as Interviewee Two found, "websites tend only to give information about current products and very little detail about editions".

\subsubsection{Other sources of information about cartographic materials}

Interviewees identified a number of other sources of information about cartographic materials, such as serials, direct marketing by suppliers, map shops, staff and/or students of institutions. These were generally unpredictable sources of information. Interviewees suggested that still only a few journals review or even list upand-coming NZ cartographic materials. Some reviews and advertising of cartographic 
materials appeared in serials such as Datum, NZ Map Society journal, New Zealand libraries, New Zealand Geographer, Notices to Mariners, and local newspapers.

Two sources of information that appear to have changed are map shops and the direct marketing by suppliers of cartographic materials. Interviewees indicated that knowing all the map suppliers and having regular contact with them is also important in identifying new materials. While interviewees suggested that this has always been important, what has changed in cartography and mapping has been the involvement of some larger map shops in publishing their own digital cartographic materials (e.g., Map shop's Topomap 2.0).

Interviewees implied that the increase in mapping organisations had led to an increase in the amount of direct marketing by private organisations - the posting of advertising material about new cartographic materials. Interviewees thought that they were receiving too little direct marketing of core cartographic materials (e.g., official maps) and too much direct marketing about tourist maps or similar less required items.

Accompanying the public good element in mapping appeared to have been a concern for keeping the public and institutions that provide the public access to cartographic materials (e.g., libraries) informed about publications. With the change in ethic has come a lack of a concern for informing map libraries about new publications. Although some interviewees indicated that they have regular contact with official mapping agencies, their: "name seems to fall of the organisations' lists for information

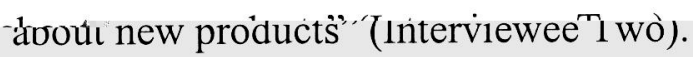

\subsection{Conclusion}

The aim of this chapter was to describe the interviewees' approaches to identifying cartographic materials and sources of maps and cartographic materials for their collections. Interviewees made several overall comments about tools available to them to identify new cartographic materials. Firstly, the timeliness of information (viz a viz new publications) is usually poor, or not well circulated. Secondly, there is a lack of comprehensive and systematic tools or methods for identifying cartographic materials. Thirdly, there is insufficient information about electronic cartographic materials produced in or about New Zealand. Finally, the identification of cartographic materials for their collections now requires much more time and effort than in the past. The non- 
reporting to the national bibliography, the fragmentation of the publishing process, and the changes in the direct distribution of new cartographic materials to map libraries has lead to the identification stage of the selection process becoming "more active than in the past" (Interviewee Five). The next chapter discusses the impacts changes in cartography and mapping have had on the evaluation and the final decision on whether to acquire or not cartographic materials. 


\section{EVALUATION AND SELECTION DECISIONS}

\subsection{Introduction}

Once cartographic materials were identified, the interviewees evaluated whether or not the materials were within scope for their collections or not. They were then in a position to make a decision whether or not to acquire materials. How complicated these stages of the selection process became depended on the nature and characteristics of cartographic materials.

Describe the impact of changes in cartography and mapping in New Zealand on the approaches of specialist map libraries in New Zealand to evaluating cartographic materials and sources of cartographic materials; and

Describe the impact of changes in cartography and mapping in New Zealand on the selection decisions specialist map libraries in New Zealand.

\subsection{Evaluation criteria}

All five map librarians had clear evaluation criteria for hardcopy cartographic materials. The three of the four libraries that had collection development policies had formal criteria outlined in their policies that selectors could follow when evaluating of cartographic materials for their collections. The interviewees identified the following range of criteria for evaluating cartographic materials:

- Content relevance to user information needs;

- Content relevance to scope of collection;

- Geographic coverage;

- Depth of collection for a particular area;

- Authority of publisher/cartographer;

- Reliability and accuracy;

- Date or currency;

- Language; 
- Scale; and

- Cost.

The interviewees placed emphasis on the subject content of the materials and its relevance to the libraries' information requirements, and the authority of the publishers/cartographers. When considering the relevance of materials, the interviewees not only kept in mind the scope of the collection, but also the usefulness of the materials:

Basically, the information contained in the item needs to fit in with the scope of the collection policy. You have to make a judgement call about the usefulness of the item, either now or in the future... (Interviewee Three)

Three important aspects of the content highlighted by the interviewees were the subject, or thematic content, the geographic coverage and the scale. As Interview Three suggested, day to day user requests for information affected their evaluation:

I am always thinking about how an item will assist with an enquiry as well as responding directly to requests or recommendations.

At the same time, the interviewees' perception of authoritativeness of publishers, and building-up some kind of history of dealing with them were essential aspects of the evaluation of materials:

I give most weight to the authority of the organisation producing the cartographic material (Interviewee One).

In addition to formal selection criteria, the librarians' familiarity with materials and their medium were significant components of evaluating materials. As they gained more experience in identifying, applying the collection criteria, and generally working with cartographic materials, they developed a 'feel' for knowing whether materials fall into the evaluation criteria or not:

Most of the time I use my instinct. I have been the map librarian for a long time (Interviewee Three).

Sometimes when evaluating New Zealand and Pacific cartographic materials, according to some interviewees, they had no choice about whether or not to purchase material because often there were no other alternatives. 
Finally, interviewees suggested that they generally had to rely on their own judgement, because New Zealand cartographic materials were seldom reviewed or evaluated to the extent that the librarians could rely on independent, or outside review processes. Furthermore, in some instances, the reviewing processes were sometimes too "slow", and the reviews were "obsolete as soon as published. The materials were out of print" (Interviewee Five).

\subsection{Criteria for new materials}

According to the interviewees, the main criteria used for evaluating hardcopy cartographic materials, such as authority of producers and cartographers and relevance of the content of materials, continued to be the most important when evaluating electronic materials. But interviewees suggested that the process of evaluating electronic materials was less automatic or instinctive because electronic materials were simply more complex:

It takes a lot more time to evaluate electronic materials. There is more to consider and I am not so familiar with them (Interviewee Five).

And Interviewee Three explained that:

I understand paper maps very well, but I do not understand the new technologies very well. So I need assistance with some products.

They also found that the identification of important information about the content (scope, subject, scales, currency of spatial data or information) of electronic cartographic materials was often more complicated than when working with hardcopy cartographic materials:

It is really important that the mathematical metadata is easily found on the output, which is not always the case with the new products (Interviewee Two).

Interviewees thought that consideration of the authority of new materials required more investigation than previously, especially when there were new mapping agencies or organisations involved. The changes that had occurred in mapping in New Zealand had affected the interviewees' confidence in some producers and materials, and they were especially suspicious of some new producers of cartographic materials: 
Apart from finding out who is producing cartographic materials, because of the numbers involved, those organisations are usually unknown quantities. So I am usually unsure about the authority of their work and you do not know if they are going to survive. They do not have a reputation (Interviewee One).

Statistics New Zealand, for example, have produced the last two Supermap products. Now, they have left it to the market to come up with a similar product. Now, there are two different organisations that I have to deal with, and I do not know much about the authority and reliability of either.

When evaluating electronic cartographic materials they considered some additional criteria or concerns about evaluating electronic cartographic materials that need consideration. The extraordinary technological, licensing and cost issues were discussed by the interviewees, but as issues secondary to the primary evaluation criteria:

With an electronic product, reliability does not only refer to the data or the presentation of information, but also the underlying [computer] system that drives the product (Interviewee Four).

The main approach that the interviewees used to overcome some difficulties of evaluating electronic cartographic material was to make use of experts from other library or university departments:

I get some advice from people in the Geography Department about the content of electronic materials. I may ask someone to test the product. We have some computing people who I talk to about new electronic products and what sort of computing equipment I need to run the programmes (Interviewee Five).

When interviewees needed to consider and negotiate licensing agreements, interviewees used two approaches. They consulted a library expert in copyright and licensing agreements for electronic materials who not only gave advice but also could assist in formal negotiations. They also consulted widely around their organisations about licensing. The main issues that arose, in addition to the sheer financial cost of the agreements, initially included ascertaining who in their wider institutions might like to have access to materials and, secondly, balancing "the potential number of users with the license costs of loading the product on a PC, or a couple of PCs, or across a [local] network" (Interviewee One). Overall, they indicated that they lacked experience in dealing with these legal issues. 
Ideally, interviewees believed that cost of materials should be a secondary evaluation criterion. However, the generally higher cost of electronic materials and the supporting technology meant that cost was ever-present at the back of their minds when evaluating electronic materials:

Cost is always a consideration. It is now becoming more of a consideration every year (Interviewee One).

However, as secondary issues, technological requirements, licensing terms and costs tended to be considered after items were selected on the basis of the primary criteria such as authority and content:

I tend to select the product, then think about the computer requirements. Not the other way around (computer then match the cartographic material) (Interviewee Four).

Overall, interviewees believed that evaluating electronic material required more input from the librarians than the traditional materials. Evaluating and negotiating electronic materials often required a lot of time and skills, and interviewees sought advice from people outside the library.

\subsection{Selection decisions}

While the map librarians generally had the freedom to make the final decision to acquire hardcopy cartographic materials, the process of making the final selection decision for electronic materials tended to be more involved. Interviewees highlighted three reasons for this. Firstly, expenditure on any single item may be set at a specific level, and electronic cartographic materials were more likely to exceeded those limits. In instances when items exceed those limits, recommendations for purchase had to be made to either to the head librarian, or a library management or trust committee:

If something costs more than $\$ 500$, then I have to run it by our Head of Department. It is more likely that electronic cartographic materials will fall into this area (Interviewee One).

In some cases, external funding was sought, and the decision to acquire a product was contingent on receiving that additional funding. Other interviewees had the 
authority to make decisions about acquisitions for their library without being required to invoke other formal procedures.

Secondly, when cooperative arrangements to share the cost of acquiring to electronic materials with other departments had been proposed, the final decision making usually required the involvement of representatives of the other departments as well as the map library. Interviewee Three suggested that deciding on whether to purchase networked items in particular involved more people:

There is a lot more cooperation and consultation before we acquire digital items that are going to be networked because different people need to be consulted and involved.

Thirdly, more information about electronic cartographic materials had to be gathered by librarians, and because of the nature of electronic materials, the information gathering process demanded more time and effort, by a larger group of people.

\subsection{Conclusion}

This chapter aimed to describe the how changes in cartography and mapping in New Zealand had impinged on the approaches of the interviewees for evaluating cartographic materials and sources of cartographic materials for their collections. Overall, interviewees indicated that the process of evaluating electronic materials took more time, they had to consider more factors when evaluating items, and they tended to be more careful about the final selection decision. More often than not, at the moment, they sought advice from people with expertise (e.g., GIS technicians, computing staff, or lecturers in geography) about the technological requirements for the materials, use of the item, or about the subject content of the cartographic material. 


\title{
DISCUSSION AND CONCLUSIONS
}

\author{
PRACTICAL STRATEGIES AND THE \\ RESHAPING OF MAP LIBRARIES
}

\subsection{Introduction}

The goals of this research project were to describe the kind of work that the interviewees, as selectors of cartographic materials, do, and the various ways their work has been impinged upon and changed in response to changes in related technologies and techniques and methods of storing, conveying and analysing spatial data and information. The research project began by broadly outlining changes that have occurred in mapping and patterns of communication of spatial information world-wide and in New Zealand, and how these changes have affected map library collections. The future success and direction of map libraries, it was suggested, are dependent on whether map librarians could adapt their collections to meet the challenges of continuing to provide user access to new cartographic materials (Perkins and Parry, 2001). Some observers articulated views that the future of map libraries may be in doubt unless radical changes are implemented (Keller, 2000). More moderate views saw the future of map libraries dependent on the development and implementation of practical management mechanisms specific to the external and internal circumstances of the library (Millea, 2001). In this chapter, I revisit the literature on selection practices libraries in light of the findings of my research.

\subsection{Policy formation and the nature of current collections}

Map libraries in New Zealand have responded to the collecting of electronic cartographic materials in a similar manner to overseas libraries (McGlamery, 2001). The visions for New Zealand map libraries that emerge in this research are that they are 
repositories of spatial information, or processed data. One of the fundamental parameters that defines the scope of their collections is that they collect 'final products', regardless of format. The GIS products and data that are available through libraries are at most interactive and users are expected to work mostly by themselves.

Interviewees expected that the proportion of electronic materials in their collections would increase, but slowly and in response to user requirements over time. Overall, this research indicates that New Zealand map libraries are pursuing a more traditional approach (Parry, 1995). Where they are offering interactive cartographic materials, they are generally using the expertise and collections of local GIS laboratories to obtain access to software and spatial information. These systems enable users to produce ondemand maps to their own specifications. Taking advantage of Intranet networking, they are able to share resources with the local GIS laboratories, and provide GIS resources in tandem with their conventional materials (Perkins, 1995). One library was beginning to play a minor role in a venture to establish a collaborative (Perkins, 1995) digital spatial library on a university campus.

Libraries also tend to respond to user requirements for specific materials rather than developing an overall collection policy framework or direction that state the current and future place of electronic cartographic materials in their collection and services, and how they would be integrated into the overall collection. This is despite the future visions of the librarians including a range of electronic cartographic materials. Only one library had a current and relatively forward looking policy for integrating hardcopy and electronic cartographic materials into its collection.

The availability of spatial information via Internet and Intranet networks enables the map libraries to offer users the use of cartographic materials that they might not otherwise be able to. The location of the map libraries in larger institutions where a range of electronic cartographic materials are available and where other staff have expertise in using those materials facilitates libraries' access to such materials. Establishing ongoing relationships with these other staff and departments is important to the development of electronic cartographic materials in their collection.

\subsection{Identification of cartographic materials}

Interviewees indicated that they were having to devise new strategies for finding enough detailed information about cartographic materials to make comparisons with 
their existing holdings. Sources of information about cartographic materials and indeed the materials themselves lack detailed information about editions and versions, even on paper materials. While the literature did not raise these issues directly, Fairbairn (1993) raised related issues that concerned the definition of a new edition. Millea (2001) suggested that map libraries move away from selecting cartographic materials based on the traditional concept of editions, to acquiring regular (e.g., annual) snapshots of electronic spatial databases.

Forer (2001) argued that the relationship between producers of cartographic materials and map libraries has become more complex. Similarly, the interviewees indicated that the following changes in organisations involved in mapping in New Zealand have affected the identification of cartographic materials: an increase in the number of organisations involved in mapping; the fragmentation of the process of publishing from marketing and distribution of cartographic materials; the increasing target-marketing of the production of cartographic materials; and the reduction in the 'public good' ethic in official mapping agencies. As a result, selectors have to spend more time and effort sourcing information about producers of cartographic materials: there is a greater amount of information to sort through, the information itself is more difficult to source than previously, and identifying who is responsible or from whom information can be sourced is not always clear.

\subsection{Tools and methods for identifying items}

The lack of good, regularly published and systematic tools for selecting cartographic materials in New Zealand requires selectors to devote an increasing amount of time trying to identify new cartographic materials. The timeliness of tools and the general lack of detailed information about new materials were two main issues raised by interviewees. In addition, selectors are having to acquire new skills in the area of using electronic sources of information about cartographic materials and electronic cartographic materials per se. Parry (2001) and Perkins (1994; 2001) also suggested that the emergence of electronic cartographic materials made the process of selection more difficult and demanded a greater level of skills from selectors. Both the literature and the findings of this research indicate that identification of new cartographic materials is no-longer the relatively 'passive' process that it had been in the age of (often) free distribution of cartographic materials and information about new materials to specialist 
map libraries in New Zealand. Identification has become a much more 'active' process, which required selectors of cartographic materials to do more research on sources than was required in the past.

At the time of writing up this dissertation, map librarians were considering a strategy to overcome some of the difficulties encountered when identifying new cartographic materials and their sources. A workshop was organised to take place at the Map Society's 2002 conference about developing a current awareness service for map librarians in New Zealand. The purpose of the workshop was to "organise some sort of pooling of awareness so map librarians all have the opportunity to purchase newly published cartographic materials" (J. Robson, personal communication, 01/12/01) ${ }^{6}$. The findings of this research project in relation to identification of new cartographic materials would suggest that in developing a current awareness strategy, not only should strategies for "pooling of awareness" be considered, but also the kind and level of cartobibliographic information required by selectors be discussed.

\subsection{Extension of evaluation criteria}

Interviewees indicated that the increasing complexity of electronic cartographic materials and the reshaping of the mapping industry in New Zealand has impinged on the evaluation of cartographic materials. The interviewees developed or considered some additional criteria for evaluating new types or formats of electronic cartographic materials. However, they still emphasised primary criteria such as reputation of the producers and the relevance of content of cartographic materials. This reflects the maxim that "at the end of the day, the information world is about content" (Demas, 1998, 155). Larsgaard $(1998,7)$ also highlighted a continued reliance on 'traditional' evaluation criteria:

Selection is exercised for digital formats as it is for hardcopy formats; although now we carefully scrutinise any licensing agreements, and we view documentation with an eagle eye.... But we still judge the quality of an item by its source's reputation and by reviews.

Furthermore, interviewees also indicated that evaluating electronic cartographic materials was more time consuming than that of conventional materials because of their

\footnotetext{
6 A report on the workshop will be published in the next New Zealand Map Society Journal in 2002.
} 
greater complexity, the unknown nature of some new entrants into the mapping industry, and map librarians' lack of experience in dealing with some electronic materials (e.g., interactive and dynamic materials).

Map librarians make increasing use of other people's expertise when evaluating materials and tackling extra issues such as the need for supporting technologies (ie, software and hardware), and copyright and contractual obligations. There are additional issues such as intellectual property rights and licensing agreements to consider, however, these are secondary considerations when the interviewees evaluate cartographic materials. More important are, firstly, the reputation of the producers of the materials and, secondly, the content of the materials. The librarians are less likely to be familiar with the reputation of the new entrants into the mapping industry and, are therefore more suspicious of them. When evaluating the relevance of the content (e.g., subject, mathematical) of the materials is important, however, because of the sophistication of some new types or formats of cartographic materials, the librarians at times consult outside experts to get assistance in evaluating electronic materials.

\subsection{Final selection decisions}

Two main issues concern the final decision about whether or not to select materials for collections. Firstly, most libraries have existing procedures for dealing with expensive items. These procedures are more often invoked because electronic resources are generally more expensive than conventional materials, and they often have other resourcing implications (e.g., issues about supporting technologies). Secondly, the final decision whether or not to acquire electronic materials usually takes more time than with conventional materials because they generally involve more people and therefore require more time to process.

\subsection{Practical strategies}

The research indicate that specialist map libraries in New Zealand have developed some practical strategies for dealing with the changes that have occurred in cartography and mapping. 


\subsubsection{Collection policies}

Map librarians have clear visions for the future direction of their libraries' collections, which includes the gradual integration of electronic cartographic materials into their collections. However, their current collecting activities tend to be ad hoc rather than according to strategic or overall planned policies. Larsgaard (1998) recommends that clear and specific guidelines and parameters on the collection of electronic cartographic material should be included in collection development policies, and that policies should be updated regularly - the process of developing policies is as important as the final policy document. Simply adding "yes, we collect that [format] also" is not enough because of the special nature and additional requirements of digital material (Larsgaard, 1998, 5). Nevertheless, Larsgaard $(1998,6)$ still emphasised that subject content is still "the most important point" in a collection policy.

\subsubsection{Skills}

Map librarians are developing new skills in using new tools and methods of identifying cartographic materials, and in developing procedures for identifying and distinguishing between editions and versions of cartographic materials. However, they are not confident in using electronic cartographic materials. Becoming more skilled and experienced with the technology is essential for developing collections (Perkins, 1994).

\subsubsection{Collaboration}

Collaboration between map librarians and staff outside of their immediate organisation is evident in the work of the interviewees. Interviewees were positive about their collaborations with other staff and departments, and there are indications that such relationships are essential to their future development. According to Larsgaard (1998, 8), the extra work required to deal with electronic cartographic materials while still developing traditional collections has, roughly speaking, lead to "as much as double" the workload for map librarians. There is therefore an increased need for collaboration in the selection of cartographic materials with the same amount of staff.

An area of collaboration that librarians are not using fully is the National Library's Te Puna union catalogue. Interviewees suggested that Te Puna was an under-used tool and that the input of a greater number of map libraries would enhance the usefulness of the tool. 


\subsection{Future research}

The development of practical strategies has been to some extent limited by the lack of research in areas associated to map librarianship in New Zealand and overseas. This research project provides a solid foundation for further research into map libraries. The interview data provide fertile information for the development of concepts for new research and areas of questioning. In particular, further research is required into the relationships that the map libraries are developing in order to provide access to electronic cartographic materials. This area of their services will undoubtedly grow.

The lack of information about the mapping industry and requirements of users of spatial information in New Zealand to some extent limits the findings of this research. To date, there has been no rigorous study of these two settings. Any future research into map librarianship and other corresponding services that provide access to spatial data and information would greatly benefit from greater understanding of which cartographic materials are being produced in New Zealand and the spatial information needs of users. 


\section{BIBLIOGRAPHY}

Aitken, G. D., G.V. O’Malley, and H.E. MacFarlane. 1993. Maps and Tomorrow's Libraries: a Map Producer's View. New Zealand Map Society Journal, no. 7: 115-125.

Alford, L. P. 2000. The impact of digital resources on organization and management of collection development and acquisitions. http://www.ifla.org/IV/ifla66/ papers/168-180e.htm. (Accessed 26-Nov-01)

Barton, P. 1978. New Zealand Maps: Selection and Acquisition. New Zealand Libraries, 41: 76-77.

Barton, P. 1979. A Guide to the Selection and Acquisition of New Zealand Maps. Bulletin, Geography \& Map Division, Special Libraries Association, 116:36-39.

Barton, P. 1981. Map Collections and Map Librarianship in New Zealand: a Synopsis. Library Trends, 29: 537-545.

Budd, J.M., and B.M. Harloe. 1997. The future for collection management. In Gorman, G.E., and R.H. Miller, eds. Collection management for the $21^{\text {st }}$ century. Westport, Connecticut: Greenwood Press, 3-28.

Bühler, J. 1999. Digital Maps in Map Collections - Presenting New Electronic Media. LIBER Quarterly, 9 (2):228-234.

Collins English dictionary and thesaurus. Glasgow: HarperCollins, 1993.

Davis, T.L. 1997. The Evolution of Selection Activities for Electronic Resources. Library Trends 45(3): 391-403.

Demas, S. 1989. Mainstreaming Electronic Formats. Library Acquisitions: Practice \& Theory 13: 227-232.

Demas, S. 1998. What Will Collection Development Do? Collection Management, 22(3/4): 151-159.

Dorling, D., and D. Fairbairn. 1997. Mapping: ways of representing the world. London: Longman.

Dorner, D.G. 2000. The blurring of boundaries: digital information and its impact on collection management. In G. Gorman. ed. International yearbook of library and information management, 2000/2001, 15-44.

Edelman, H. 1979. Selection Methodology in Academic Libraries. Library Resources \& Technical Services, 23(1): 33-38.

Fairbairn, D. 1993. The Future History of Our Landscape. The Cartographic Journal, 30(1): 62-67.

Forer, P. 1993. Accessing Digital Data in Map Libraries. New Zealand Map Society Journal 7: 103-114. 
Forer, P. 2001. Taking care of business: map libraries and the new 'mapping' industry. In R.B. Parry, and C.R. Perkins, eds. The map library in the new millennium. London: Library Association Publishing, 188-206.

Goodchild, M. 2000. Geographic information systems. In R.J. Johnston, D. Gregory, G. Pratt, and M. Watts. eds. The dictionary of human geography. Oxford: Blackwells.

Gorman, G.E., and P. Clayton. Qualitative research for the information professional: a practical handbook. London: Library Association Publishing.

Gorman, M. 1999. Metadata or Cataloguing? A False Choice. Journal of Internet Cataloguing 2(1): 5-22.

Hazen, D.C. 1990. Selection: function, models, theory. In C.B. Osburn, and R. Atkinson. eds. Collection management: a new treatise, vol. 26b. Greenwich, Connecticut: JAI Press, 273-300.

Howard, G., R. Pickering, and D. Mole. 1999. A national topographic database for the $21^{\text {st }}$ century - paradigm shifts in business process and technology. In C. P. Keller. ed. Touch the past, visualize the future : proceedings : $19^{\text {th }}$ International Cartographic Conference and $11^{\text {th }}$ General Assembly of ICA, Ottawa, Canada, 1999. Ottawa : International Cartographic Association, vol. 1: 103-114.

Johnston, P. 1997. Collection development policies and electronic information resources. In Gorman, G.E., and R.H. Miller, eds. Collection management for the $21^{\text {st }}$ century. Westport, Connecticut: Greenwood Press, 83-104.

Jones, C. 1997. Geographical information systems and computer cartography. Essex, U.K.: Longman.

Keller, C.P. 2000. Thoughts on the Future of the Map Library. New Zealand Map Society Journal, no. 13:1-12.

Kelly, J. 1993. Cartography, Map-making and GIS. New Zealand Cartography and Geographic Information Systems 23(2): 1-8.

Kraak, M.J. 2001. Web resources and the map library. In R.B. Parry, and C.R. Perkins, eds. The map library in the new millennium. London: Library Association Publishing, 103-116.

Larsgaard, M.L. 1998. Map librarianship: an introduction, $3^{\text {rd }}$ ed. Englewood, Col.: Libraries Unlimited.

MacEachen, A.M. 1995. How maps work: representation, visualization, and design. New York: Guilford Press.

McGlamery, P. 2001. New technologies in the map room. In R.B. Parry, and C.R. Perkins, eds. The map library in the new millennium. London: Library Association Publishing, 43-55.

Millea, N. 2001. Organisational change. In R.B. Parry, and C.R. Perkins, eds. The map library in the new millennium. London: Library Association Publishing, 28-42. 
Minister of Land Information New Zealand. 1999. Minister announces huge fee drop for topographic data. http://www.linz.govt.nz/publications/media/press releases/FeeDrop.html (accessed 05/02/2002)

Moellering, H. 1980. Strategies of Real-time Cartography. The Cartographic Journal 17(1): 12-15.

Moellering, H. 1984. Real maps, virtual maps and interactive cartography. In G.L. Gaile, and C.J. Willmott. eds. Spatial statistics and models. Dordrecht, Holland: D. Reidel Pub.: 109-132.

Monmonier, M.S. 2000. Map image and map. In R.J. Johnston, D. Gregory, G. Pratt, and M. Watts. eds. The dictionary of human geography. Oxford: Blackwells.

Monroe, W.S. 1997. The role of selection in collection development: past, present, and future. In G.E. Gorman, and R.H. Miller, eds. Collection management for the $21^{\text {st }}$ century. Westport, Connecticut: Greenwood Press, 105-118.

Norman, O.G. 1997. The Impact of Electronic Information Sources on Collection Development: A Survey of Current Practice. Library Hi Tech 15(1-2): 123-132.

Parry, R.B. 1995. Leave It to the Labs? Options for the Future of Map and Spatial Data Collections. LIBER Quarterly 5(3): 312-29.

Parry, R.B. 1999. Finding Out About Maps. Journal of Higher Education 23(2): 265271.

Parry, R.B. 2001. Offline digital maps. In R.B. Parry, and C.R. Perkins, eds. The map library in the new millennium. London: Library Association Publishing, 72-87.

Parry, R.B., and C.R. Perkins. 2000. World mapping today, $2^{\text {nd }}$ ed. London: BowkerSaur.

Parry, R.B., and C.R. Perkins. 2001. Introduction. In R.B. Parry, and C.R. Perkins, eds. The map library in the new millennium. London: Library Association Publishing, 1-11.

Patton, M.Q. 1980. Qualitative evaluation methods. Beverly Hills, Calif.: Sage.

Perkins, C.R. 1987. Map acquisition. In R.B. Parry, and C.R. Perkins World mapping today. London: Butterworths, 15-26.

Perkins, C.R. 1994. Quality in Map Librarianship and Documentation in the GIS Age. The Cartographic Journal, 31: 93-99.

Perkins, C.R. 1995. Leave it to the Labs? Options for the Future of Map and Spatial Data Collections. LIBER Quarterly 5(3): 312-329.

Perkins, C.R. 2001. Access to maps and spatial data. In R.B. Parry, and C.R. Perkins, eds. The map library in the new millennium. London: Library Association Publishing, 157-175.

Perkins, C.R., and R.B. Parry. 1996. Mapping the UK. London: Bowker Saur. 
Perkins, C.R., and R.B. Parry. 2001. Is there a future for the map library? In R.B. Parry, and C.R. Perkins, eds. The map library in the new millennium. London: Library Association Publishing, 246-255.

Peterson, M.P. 2001. Maps and the Internet. In R.B. Parry, and C.R. Perkins, eds. The map library in the new millennium. London: Library Association Publishing, 88102.

Project Steering Committee. 2001. A digital map library and spatial data collection: application to the Vice Chancellor's Development Fund. Unpublished memorandum.

Rhind. D. ed. 1997. Framework for the world. Cambridge, U.K.: GeoInformation International.

Rice-Lively, M.L. 1997. Analysing qualitative data from information organisations. In G.E. Gorman, and P. Clayton. Qualitative research for the information professional: a practical handbook. London: Library Association Publishing, 198-221.

Ristow, W. W. 1980. The emergence of maps in libraries. Hamden, Conn.: Linnet Books.

Robinson, A. H., R.D. Sale, J.L. Morrison, and P.C. Meuhrcke. 1984. Elements of cartography, $5^{\text {th }}$ ed. New York: Wiley.

Robertson, W.A., and C. Gartner. 1997. The reform of national mapping organisations: the New Zealand experience. In D. Rhind. ed. Framework for the world. Cambridge, U.K.: GeoInformation International.

Robson, J. 2001. NZ Map Society Conference organiser. Personal communication.

Singleton, R.A., B.C. Straits, and M.M. Straits. 1993. Approaches to social research, $2^{\text {nd }}$ ed. New York. Oxford University Press.

Small, D. 2001. Alexander Turnbull Library cartographic curator. Personal communication.

Smith, A. G. 1997. Testing the Surf: Criteria for Evaluating Internet Information Resources. The Public-Access Computer Systems Review 8(3).

Vasiliev, I., S. Freundschuh, D.M. Mark, G.D. Theisen, and J. McAvoy. 1990. What is a Map? The Cartographic Journal 27: 119-123.

Virgil L., P. Blake, and T.T. Surprenant. 2000. Navigating the Parallel Universe: Education for Collection Management in the Electronic Age. Library Trends 48(4) (unpaginated, accessed via InfoTrac Database, 26-Nov-01).

Visvalingham, M. 1989. Cartography, GIS and Maps in Perspective. The Cartographic Journal 26: 26-32. 


\section{APPENDICES}

\section{Appendix One: Information sheet to accompany consent form.}

Mark Bagnall

Potential participant's name

and address

Dear (potential participant's name),

In order to complete a Masters in Library and Information Studies, I am required to undertake an individual research project. I have chosen to investigate what effects changes in cartography and mapping have had on the selection of New Zealand cartographic materials for New Zealand's specialist map libraries. I am seeking participants who are willing to be interviewed by me on selection practices in their map library.

Your participation in this project would involve a telephone interview, which should take between 30-45 minutes. The results of the project may be published, or presented at a conference, but you may be assured of the complete confidentiality of data gathered in this investigation: non-attributable quotations may be used. To ensure confidentiality, only my supervisor and I will have access to the information obtained from you, and I will keep the data in secure storage for up to two years at which point they will be destroyed.

\section{Some important definitions or ideas}

In the interview, I may refer to the following terms or ideas:

Changes in cartography - range from changes to data gathering, map design and map production theory and techniques, to recent developments in theory of understanding.

Cartographic materials are products that convey data or information on geographic features and their relationships in space. It includes tangible (hardcopy)

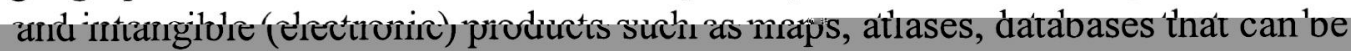
locally or remotely stored or accessed.

Mapping is the production cartographic materials, from data gathering to the printing or design of output of spatial information. 
The key areas of questioning will be:

Important influences on selecting information resources

- Influences on selecting information resources

Description of the map library, its collection and services

- Scope of the collection

- Essential characteristics of the collection (e.g., types of information resources accessible, extent etc.)

- Brief history of the library

\section{Selection philosophy and policy}

- The overall vision for the collection

- Whether selection follows a formal written document

- How digital materials have been integrated into the collection

- The overall processes of selection of materials for the collection

\section{Identification of materials and sources of materials for collections}

- The methods for finding out information about new cartographic materials

- The means or tools you use to identify potential materials and sources of materials for the collection

- Whether there are any library collections that are not physically part of the library that are regarded as essential to the collection (either that are accessed via the Internet or Interlibrary loan or other arrangements)

- The impacts that changes in cartography and in mapping in New Zealand have had on the identification of new cartographic materials and sources of products

\section{Evaluation of materials and sources of materials for collections}

- The procedures used to evaluate materials for selection and deselection

- Evaluation criteria

- The impacts that changes in cartography and mapping in New Zealand have had on the criteria used to evaluate new products for the collection

\section{Selection of materials and sources of materials for collections}

- The final decision making processes for selection and deselection of materials for the collection

- The impacts on these processes by changes in cartography and mapping in New Zealand

- Who are involved in the selection processes

- The impacts of changes in cartography and mapping in New Zealand on library users' information needs, demands and use

\section{General comments}

- Any additional comments or information 
Please can you send copies of the following documents or information to the researcher (a self-addressed, postage prepaid envelope can be sent to respondents).

- Information sheets about the map library, its collection and services

- The map library's selection policy (or collection management policy if the selection policy is part of it).

Please do not hesitate to contact me, or my supervisor, Dr. Dan Dorner, to discuss any aspect of the research or your participation. I can be contacted at 04My supervisor's address is Dr. Dan Dorner, School of Information Management, Victoria University, PO Box 600, Wellington, Ph. 04-------. This project complies with the Victoria University of Wellington Faculty of Commerce and Administration's Human Ethics Committee guidelines.

Thank you for your time.

Mark Bagnall 


\section{CONSENT FORM \\ FOR INTERVIEW SUBJECTS}

\section{Research Project:}

The impact of changes in cartography and mapping in New Zealand on the selection of cartographic materials for map libraries.

I have read and understood the description of the above-named project and am aware of what is required of interviewees.

I understand that no data will be directly attributed to me in transcripts or in the final report.

I consent to publication of the results of the project with the understanding that my confidentiality will be preserved.

I understand also that I may at any time withdraw from the project without explanation prior to the researcher commencing analysis of the interviews, which will occur on 15 January 2002.

I do/do not (delete one) wish to receive a copy of the summary of findings which will be made available on completion of the research.

Based on above these conditions, I agree to take part in an interview as outlined in the accompanying Information Sheet.

Name:

Signed:

Date: 


\section{Appendix Two: Questions for GIS laboratory managers or technicians.}

\section{Questions}

1. What effects do you think changes in methods of conveying spatial data and information (e.g., the emergence of dynamic cartographic materials) and in the publication of spatial data and information have had on map library collections in New Zealand?

2. What distinguishes the kinds of spatial data and information collected by your GIS laboratory from those collected by the university map library?

3. What kind of relationship does your GIS laboratory have with the university map library? (e.g., financial, technical or other support, access to each others collections, etc.)

Do you see this changing? If yes, how?

4. What input, if any, does the library have into the collection of spatial data and information for your GIS laboratory?

5. Has the GIS laboratory developed largely independently to the map library? If yes, can you explain in your opinion why?

6. Are you working, or have you worked, together with the map library staff on projects? If yes, what is the nature of those projects? 